OPEN ACCESS

Edited by:

Michael Gänzle,

University of Alberta, Canada

Reviewed by:

Susan M. Tosh,

University of Ottawa, Canada

Carlos Gómez-Gallego,

University of Eastern Finland, Finland

*Correspondence:

Cormac G. M. Gahan c.gahan@ucc.ie

Specialty section:

This article was submitted to Nutrition and Microbes,

a section of the journal

Frontiers in Nutrition

Received: 03 July 2019 Accepted: 23 October 2019 Published: 27 November 2019

Citation:

Joyce $S A$, Kamil A, Fleige $L$ and Gahan CGM (2019) The Cholesterol-Lowering Effect of Oats and Oat Beta Glucan: Modes of Action and Potential Role of Bile Acids and the Microbiome. Front. Nutr. 6:171. doi: 10.3389/fnut.2019.00171

\section{The Cholesterol-Lowering Effect of Oats and Oat Beta Glucan: Modes of Action and Potential Role of Bile Acids and the Microbiome}

\author{
Susan A. Joyce ${ }^{1,2}$, Alison Kamil ${ }^{3}$, Lisa Fleige ${ }^{3}$ and Cormac G. M. Gahan ${ }^{1,4,5 *}$ \\ ${ }^{1}$ APC Microbiome Ireland, University College Cork, Cork, Ireland, ${ }^{2}$ School of Biochemistry and Cell Biology, University \\ College Cork, Cork, Ireland, ${ }^{3}$ Quaker Oats Center of Excellence, PepsiCo R\&D Nutrition, Barrington, IL, United States, \\ ${ }^{4}$ School of Microbiology, University College Cork, Cork, Ireland, ${ }^{5}$ School of Pharmacy, University College Cork, Cork, Ireland
}

Consumption of sufficient quantities of oat products has been shown to reduce host cholesterol and thereby modulate cardiovascular disease risk. The effects are proposed to be mediated by the gel-forming properties of oat $\beta$-glucan which modulates host bile acid and cholesterol metabolism and potentially removes intestinal cholesterol for excretion. However, the gut microbiota has emerged as a major factor regulating cholesterol metabolism in the host. Oat $\beta$-glucan has been shown to modulate the gut microbiota, particularly those bacterial species that influence host bile acid metabolism and production of short chain fatty acids, factors which are regulators of host cholesterol homeostasis. Given a significant role for the gut microbiota in cholesterol metabolism it is likely that the effects of oat $\beta$-glucan on the host are multifaceted and involve regulation of microbe-host interactions at the gut interface. Here we consider the potential for oat $\beta$-glucan to influence microbial populations in the gut with potential consequences for bile acid metabolism, reverse cholesterol transport (RCT), short-chain fatty acid (SCFA) production, bacterial metabolism of cholesterol and microbe-host signaling.

Keywords: microbiome, microbiota, oat beta glucan, bile, propionate, cholesterol

\section{INTRODUCTION}

A significant body of evidence demonstrates that consumption of oat products is linked to a reduction in serum LDL cholesterol, a risk factor for the development of cardiovascular disease (CVD) (1-3). Oats are a source of soluble fiber in the form of $\beta$-glucan (as well as arabinoxylan, xyloglucan, and other minor components), insoluble fiber, protein, lipids, phenolic compounds, vitamins, and minerals. Whilst other constituents in oats may also have an impact, the cholesterollowering activity of oats has been demonstrated to be associated with an increase in viscosity of the gut contents (4) which enhances excretion of bile acids and cholesterol in the feces (5). Indeed, consumption of $\beta$-glucan alone can reduce serum cholesterol (6). The weight of evidence in support of a beneficial role of oat $\beta$-glucans led the US Food and Drug Administration (FDA) to authorize the use of health claims on oat products attributing lowering of CVD risk to consumption of at least $3 \mathrm{~g}$ per day of $\beta$-glucan. Cholesterol lowering claims have also been approved in the EU by the European Commission (7-9) and in a number of other jurisdictions including Australia and New Zealand (10), Canada (11), Brazil (12, 13), Malaysia (14), Indonesia (15), and South Korea (16). 
We, and others, consider that the cholesterol-lowering properties of oats may not be solely attributable to the viscous properties of $\beta$-glucans (17-19). Recent research suggests a significant role for the gut microbiota in the maintenance of cholesterol homeostasis in the host (20). A number of studies have demonstrated the efficacy of probiotics [in particular, probiotic strains with an ability to metabolize host bile acids through bacterial bile salt hydrolase (BSH) activity] in lowering cholesterol in animal models or in humans (21-25). Microbial metabolism of bile acids is known to influence systemic cholesterol metabolism. As cholesterol is a precursor of bile acids, influencing bile acid synthesis provides a means for enhanced excretion of cholesterol thereby lowering serum cholesterol levels in the host $(26,27)$. Bile acid signaling through the farnesoid $\mathrm{X}$ receptor (FXR) and other receptors may also influence host metabolism of cholesterol, for example through the induction of cholesterol transport in the gut $(27,28)$. Alterations to microbial production of short chain fatty acids (SCFA) including propionate are also likely to have consequences for cholesterol metabolism in the host (29), though the precise mechanisms remain to be elucidated (30). Importantly, oat products and oat $\beta$-glucans have been shown to modulate the gut microbiota in human, animal and in vitro fermentation systems $(19,31,32)$. Therefore, oats (including oat $\beta$-glucans) may have a dietary influence upon the host gut microbiota with consequences for bile acid signaling, SCFA signaling, and other effects that are known modulators of host cholesterol homeostasis.

Herein we review the evidence linking components of oats with alterations to host microbiota and discuss potential mechanisms by which such microbiota changes may influence host cholesterol metabolism with a particular focus upon bile acid metabolism. Whilst we appreciate that oat $\beta$-glucans may also play a role in post-prandial glucose homeostasis (33) in this review we will predominately focus upon mechanisms by which they lower host cholesterol. Our focus is primarily on the effects of oat $\beta$-glucans. However, some reference will be made to the mechanistic effects of barley $\beta$-glucans, notably in instances where relevant studies have not yet been performed using oat $\beta$-glucans.

\section{CLINICAL EVIDENCE FOR CHOLESTEROL-LOWERING PROPERTIES OF OATS}

A large number of individual randomized-controlled trials and subsequent meta-analyses have established a significant effect of consumption of oats or oat $\beta$-glucans in reducing $L D L$ cholesterol and improving other markers of cardiovascular disease (CVD) risk $(1-3,34)$. A meta-analysis of 126 individual studies by Tiwari and Cummins (1) examined the effect of $\beta$ glucan intake on measures of blood cholesterol [total cholesterol (TC) and low-density lipoprotein (LDL)-cholesterol] as well as blood glucose levels. The study demonstrated a significant reduction of TC (by $0.6 \mathrm{mmol} / \mathrm{L}$ ), LDL cholesterol (by 0.66 $\mathrm{mmol} / \mathrm{L}$ ), and TGL/TAG (by $0.04 \mathrm{mmol} / \mathrm{L}$ ) and an increase in $\mathrm{HDL}$ cholesterol (by $0.03 \mathrm{mmol} / \mathrm{L}$ ) following consumption of oat or barley $\beta$-glucan (oat and barley $\beta$-glucans are considered bioequivalent with respect to cholesterol-lowering properties). A dose response model demonstrated a decrease in TC with an increase in $\beta$-glucan dose but no increased effect in individuals consuming over $3 \mathrm{~g} /$ day $\beta$-glucan (1). This finding supports FDA recommendations relating to consumption of $3 \mathrm{~g} /$ day $\beta$-glucan to lower CVD risk (35).

Similarly a meta-analysis of randomized-controlled trials by Whitehead et al. which focused upon consumption of $\geq 3 \mathrm{~g} /$ day oat $\beta$-glucan showed a significant reduction in both TC (by 0.30 $\mathrm{mmol} / \mathrm{L}$ ) or LDL cholesterol (by $0.25 \mathrm{mmol} / \mathrm{L}$ ) (but no effect on HDL cholesterol or TGL) (2). The study found no increased effect in those consuming higher doses of $\beta$-glucan, again suggesting that a minimum recommended dose of $3 \mathrm{~g} /$ day is sufficient for the cholesterol-lowering effect and is not enhanced through consumption of higher doses.

AbuMweis et al. (36) combined the data from 11 randomizedcontrolled trials that fitted their weighted criteria based on dose, duration, source of $\beta$-glucan, population characteristics and sample size to report that interventions did elicit changes in total and LDL cholesterol levels relative to control subjects, but no dose-response was observed. Reductions in TC of $0.30 \mathrm{mmol} / \mathrm{L}$ and reductions in LDL cholesterol of $0.27 \mathrm{mmol} / \mathrm{L}$ were reported in response to consumption of $\geq 3 \mathrm{~g} /$ day barley $\beta$-glucan.

The lack of a dose-response when consuming levels of $\beta$ glucan $>3$ g/day was noted above. This lack of dose response may reflect variation in the physico-chemical properties of $\beta$-glucans used in individual randomized-controlled trials and included in the above meta-analyses. It is known that highly water soluble $\beta$-glucan of medium to high average molecular weight $\left(M_{w}\right)$ is more effective in reducing serum cholesterol than poorly water soluble $\beta$-glucan of low $M_{w}$ (37). However, the precise $M_{w}$ of $\beta$-glucan can be difficult to establish and may not be accurately reported in randomized-controlled trial data (2). It has also been suggested that the individual food matrix and/or food processing procedures may influence the $\mathrm{M}_{\mathrm{W}}$ (and therefore bioactivity) of $\beta$-glucan and that this is a further confounding factor when comparing data from individual trials (2). The influence of so many variables may suggest that particular meta-analyses are not sufficiently powered to detect a dose-effect when comparing studies which use differing forms of $\beta$-glucan with variations in viscosity and bioactivity where such parameters remain unknown $(2,36)$.

\section{BILE ACID SYNTHESIS IN THE HOST}

Bile acid synthesis and excretion is the main route by which cholesterol is effectively eliminated from the body. In the following sections we provide a basic overview of bile acid metabolism in the host with a particular emphasis upon how the gut microbiota contributes to metabolism of the bile acid pool. These concepts are further expanded in sections Alterations to Gut Microbiota and Effects on Cholesterol Metabolism and Mechanisms by Which Oat $\beta$-Glucan may Influence Host Cholesterol Metabolism Through Alterations in BSH Activity of the Microbiome below. 


\section{The Bile Acid Cycle, Cholesterol, and the Role of Microbial BSH}

Bile acids are synthesized in liver hepatocytes from cholesterol by cytochrome enzymes (CYPs). Approximately $500 \mathrm{mg}$ of cholesterol is converted to bile acid (BA) on a daily basis (38). Prior to secretion and storage in the gall bladder primary bile acids chenodeoxycholic acid (CDCA) and cholic acid (CA) are conjugated to either a taurine or a glycine molecule to aid their solubility and excretion from the liver. The majority of conjugated bile acids are reabsorbed in the terminal ileum, with $5 \%$ excreted in the feces [see (39) for a review]. Conjugated bile acids are released postprandially from the gall bladder into the small intestine and are subject to enzymatic modifications by the bile salt hydrolase (BSH) activity of the microbiota to liberate them from their cognate amino acid. This renders them susceptible to further microbial modification to form secondary bile acids lithocholic acid (LCA) from CDCA and deoxycholic acid (DCA) from CA. This activity is completed by specific members of the colonic microbiota [the Eubacterium and Clostridium XIVa clusters (40)] although gene analyses suggest that other microbial representatives may be capable of carrying out these reactions [reviewed by Long et al. (39)]. Therefore, while the liver dictates bile acid production, the gut microbiota is responsible for the diversity of BAs derived from the bile acid CA and CDCA families and it also influences reuptake or enterohepatic circulation. Alterations to the range and relative profile of bile acids is a reliable readout of microbial changes in the gut and such changes are particularly evident in disease states including metabolic syndrome, inflammatory bowel diseases and Type II diabetes [see $(41,42)$ for reviews]. Therefore, the dietary effects of oat $\beta$-glucan on the microbiota (outlined in section Alterations to Gut Microbiota and Effects on Cholesterol Metabolism), are likely to impact bile acid profiles in the host with potential consequences for metabolism and signaling.

Bile acids are ligands for the farnesoid-X-receptor (FXR) which is a nuclear receptor that is central to energy and metabolic regulation in a range of different tissues (43). Microbiallymodified and unconjugated bile acids are the most potent natural FXR ligands with CDCA $<\mathrm{LCA}<\mathrm{DCA}<\mathrm{CA}$ in order of affinity and activation strength, while ursodeoxycholate (UDCA) and murine tauro- $\beta$-muricholic acid can hinder FXR activity $(27,44,45)$. FXR is widely distributed in tissues including the intestine and the liver. FXR therefore acts as a bile acid sensor in the intestine and as a controller of bile acid synthesis in the liver (46). It controls bile acid synthesis by a variety of mechanisms. Agonism of FXR in the intestine induces production of the endocrine hormone fibroblast-growth-factor 19 [FGF19 (in humans) FGF15 (in mice)] which enters the circulation and activates specific receptors on hepatocytes to reduce bile acid synthesis (through down-regulation of a key enzyme CYP7A1) (47-49). Alternatively a reduction in engagement of the FXR may enhance expression of regulatory networks that are inhibited by FXR such as the liver orphan receptor (LXR) regulon (24). Another layer of cross-talk from the intestine to the liver acts through enterohepatic re-circulation of bile acids. On reaching the liver, circulating bile acids activate FXR directly to ultimately inhibit CYP7A1 transcription, again reducing bile acid synthesis (44).

The importance of FXR in host cholesterol metabolism is highlighted by studies using FXR knock-out mice or specific chemical agonists of the FXR [reviewed in Li and Chiang (27)]. Knock-out of FXR in mice results in elevated LDL-C (50), whereas stimulation of the FXR in hypercholesterolaemic mice (using bile acids or specific agonists) results in a lowering of HDL-C and LDL-C (51). More recently, the intestinal FXR agonist Fexaramine (Fex) was shown to induce FGF15 and to lead to broadly beneficial metabolic effects including reduced weight gain in mice fed a high fat diet (52) and reduced serum cholesterol in a mouse model of diabetes (53). The precise mechanisms by which FXR contributes to cholesterol metabolism in the host remain unclear but are thought to involve regulation of fatty acid metabolism as well as Reverse Cholesterol transport (RCT) and Trans-intestinal Cholesterol excretion (TICE) (outlined below) $(27,54)$.

\section{Reverse Cholesterol Transport (RCT) and Trans-intestinal Cholesterol Excretion (TICE)}

In addition to the incorporation of cholesterol into bile acids and subsequent bile acid excretion, other mechanisms contribute to the systemic control of host cholesterol. RCT is a mechanism for directly transporting cholesterol from the tissues to the liver for excretion into bile, and ultimately in feces. RCT relies upon cholesterol loading onto HDL particles which can remove cholesterol from the tissues, notably from macrophage foam cells in the artery wall [reviewed in Temel and Brown (55) and Tall and Yvan-Charvet (56)]. HDL-cholesterol then enters hepatocytes via specific receptors and the cholesterol is secreted directly into bile for excretion via the specific transporters ABCG5/G8. This represents a mechanism by which HDL-cholesterol is thought to be associated with reduced cardiovascular disease risk.

More recent work has revealed a supplemental system for Trans-intestinal cholesterol excretion (TICE) directly into feces through enterocytes in the proximal small intestine. The model proposes that cholesterol is removed from HDL particles in the liver and loaded onto ApoB-containing lipoproteins which migrate to the small intestine where the particles are transported across enterocytes and the cholesterol is excreted into the intestinal lumen. Again cholesterol excretion is via the ABCG5/G8 transport system, in this case expressed in enterocytes (55). Importantly genes that encode essential components of both RCT and TICE are regulated via FXR (27). These include ApoAl which encodes a component of HDL particles and the ABCG5/G8 transport system (28). This suggests that bile acid signals (and therefore the microbiota) can modulate both RCT and TICE (section Mechanisms by Which Oat $\beta$ Glucan May Influence Host Cholesterol Metabolism Through Alterations in BSH Activity of the Microbiome below). 


\section{THE VISCOUS NATURE OF $\beta$-GLUCAN AND EXISTING PROPOSED MECHANISM FOR CHOLESTEROL-LOWERING}

The $\beta$-glucan polysaccharide forms a viscous liquid suspension in solution, a characteristic which is predicted to occur under physico-chemical conditions encountered in the GI tract. Intestinal viscosity of $\beta$-glucan is determined by its concentration, solubility and $\mathrm{M}_{\mathrm{w}}$, features that may influence variation in clinical effects seen across different controlled trials. Indeed, recent studies have determined the effects of increasing viscosity upon physiological efficacy. In a large randomized controlled trial the capacity of oat products to lower serum cholesterol was directly proportional to the $\mathrm{M}_{\mathrm{w}}$ of the $\beta$-glucan component, with high $(2.2$ million $\mathrm{g} / \mathrm{mol})$ and medium $(850,000 \mathrm{~g} / \mathrm{mol}$ or $530,000 \mathrm{~g} / \mathrm{mol}) \mathrm{M}_{\mathrm{w}} \beta$-glucans significantly reducing LDL cholesterol and a low $(210,000$ $\mathrm{g} / \mathrm{mol}) \mathrm{M}_{\mathrm{w}} \beta$-glucan proving ineffective (4). Furthermore both increasing viscosity (57) or increasing $M_{W}$ (58) of $\beta$ glucan have been shown to increase the ability to regulate post-prandial glucose concentrations in human subjects. The beneficial effects of high $M_{W}$ oat $\beta$-glucan are therefore thought to be related to an ability to form a viscous solution in the intestine.

The mechanisms by which viscous $\beta$-glucans modulate host cholesterol are thought to be linked to modulation of host bile acid metabolism (59). Viscous $\beta$-glucan is hypothesized to interact with bile acids and prevent their readsorption in the terminal ileum. This results in increased fecal excretion of bile acids thereby increasing the requirement for de novo synthesis of bile acids from cholesterol, a mechanism which lowers systemic LDL cholesterol (59). In support of this, a number of animal studies $(60,61)$ and human intervention studies have shown elevated fecal bile acid excretion following consumption of oats or $\beta$-glucan (5, 62-64). This is matched by evidence for elevated de novo bile acid synthesis following consumption of oats both in animals (through measurement of activity of relevant liver enzymes including Cyp7A1) (61) or through measurement of 7 alpha-hydroxy-4-cholesten-3-one (HC) in humans (a marker for bile acid synthesis) (61, 64). A comprehensive study in pigs demonstrated that oat $\beta$-glucan feeding increased bile acid excretion during the early feeding period but that bile acid excretion actually decreased in this group following dietary adaptation. The study pointed to alterations in gut physiology, reduced bile acid uptake, and a reduction in cholesterol absorption along with possible microbiota changes that could explain the reduction in systemic cholesterol levels in the $\beta$-glucan-fed group (65). The authors indicated that oat $\beta$-glucan significantly influenced bile acid and cholesterol metabolism in the host along with a likely beneficial (prebiotic) effect on the gut microbiota which enhanced both the generation of the secondary bile acid UDCA and cholesterol digestion in the gut (65). The possible effects of such microbiota-mediated mechanisms are outlined further in the sections below.

\section{ALTERNATIVE MECHANISMS BY WHICH OAT $\beta$-GLUCAN MAY AFFECT HOST CHOLESTEROL METABOLISM}

\section{Alterations to Gut Microbiota and Effects on Cholesterol Metabolism}

Whilst the precise mechanisms remain to be elucidated it is clear that the gut microbiota plays a significant role in host cholesterol homeostasis. Very early studies indicate that antibiotic treatment of mice inhibits cholesterol metabolism leading to accumulation of systemic cholesterol (66). Also, germ-free rats accumulate greater levels of cholesterol from elevated cholesterol diets compared to conventionally raised animals (67). Germ free rats demonstrated lower levels of systemic catabolism of dietary cholesterol (68) and also showed reduced fecal excretion of both total sterols and bile acids in particular (69). The data suggest that increased bile acid synthesis from cholesterol is a mechanism for lowering of systemic cholesterol levels (68) and is influenced by the activities of the gut microbiota. Furthermore, there is significant evidence that transient alteration of the microbiota through the administration of probiotic bacteria can be beneficial in lowering of systemic cholesterol (see sections below). The data suggest a role for the microbiota in the maintenance of cholesterol homeostasis in the host and suggest that alteration of the community structure of this microbial population has the capacity to influence cholesterol metabolism (70). More detailed studies are necessary in order to pinpoint specific microbial genera or species in the gut which may influence host cholesterol metabolism. Such information is emerging for models of lipid metabolism, weight gain and adiposity. For instance, murine studies pointed to alterations in the relative ratios of two major phyla, Bacteroidetes, and Firmicutes in promoting weight gain $(71,72)$. The findings also correlated with human studies in obese volunteers subjected to a calorie-restricted diet (73) and the obesity phenotype was transferable by transplant of the microbiota from either obese mice or obese humans to microbiota naïve mice, thereby showing a functional role of the microbiota in this phenomenon (74-76). Other studies have shown a clear link between microbial gene richness and metabolic health. Individuals with low gene richness in the microbiota are more likely to display increased adiposity and dyslipidemia (77).

$\beta$-glucan is resistant to depolymerization by gastric and pancreatic enzymes and transits to the colon for microbial fermentation. Alteration of bile acid metabolism is also known to impact the microbiota (78) and is therefore a further possible mechanism by which $\beta$-glucans may modulate microbial gut populations.

There is significant evidence from models of increasing complexity (from in vitro fermentation models, to rodent to porcine models) and human intervention studies that oat fibers have a significant impact upon the compositional structure of the gut microbial community. For critical reviews of the effects of $\beta$-glucan upon the microbiota the reader is referred to Jayachandran et al. (79) and Sanders et al. (80). Relatively simple in vitro fermentation studies which mimic the human colon using human fecal bacterial populations allow for highly 
controlled analyses of bacterial responses to dietary components but lack the biological complexity of in vivo models. In vitro fermentation studies have shown that addition of oat or barley $\beta$-glucan directly promotes the growth of gut bacterial populations (including the Clostridium histolyticum subgroup and Bacteroidetes/Prevotella groups) (81). A recent study using an in vitro batch culture system demonstrated that oat $\beta$-glucan induced proliferation of Bacteroidetes but was not Bifidogenic. In contrast growth of Bifidobacteria was stimulated by oat-derived polyphenols (82). In another study oat flakes promoted growth of the Bacteroides/Prevotella group or Bifidobacterium group in a fecal slurry with effects related to the size of the oat flakes (31). A recent study indicates the ability of oat $\beta$-glucan to promote growth of Prevotella and Roseburia species in an in vitro fermentation with concomitant production of the short chain fatty acids (SCFA) propionate and butyrate (83). Overall these studies indicate that oat $\beta$-glucan and other components of whole oats can influence populations of biologically relevant bacterial taxa.

Recent studies in mice demonstrated that oat $\beta$-glucan feeding increases populations of Bacteroides species and Prevotella species whereas bacteria from the phylum Firmicutes were decreased (84). Zhou et al. similarly showed that whole grain oat flour causes significant alterations to microbiota community structure relative to a control diet with alterations to Prevotellaceae, Lactobacillaceae, and Alcaligenaceae families (85). Importantly the microbiota changes correlated with a significant lowering of total cholesterol and non-HDL cholesterol in animals fed whole grain oat flour (85). Ryan et al. showed a significant reduction in markers of cardiovascular disease risk in an $a p o E$ deficient mouse model following feeding with oat $\beta$-glucans which correlated with an increase in the population of the family Verrucomicrobia and elevated production of nbutyrate (32). This is particularly interesting as Akkermansia muciniphila (a key member of the Verrucomicrobia) has been functionally linked to improved gut barrier function, reduction in obesity, and improved metabolic health (86). Early studies in rats utilized a culture-based approach and demonstrated that feeding of oat flour formulations led to an increase in Bifidobacteria populations in the gut (87). Insoluble high viscosity oat $\beta$-glucan enriched for Clostridium cluster I in a pig model with associated increases in butyrate production (88).

When microbial composition studies were performed in humans, low $\mathrm{M}_{\mathrm{w}}$ barley $\beta$-glucan did not appear to alter microbial representation however high $\mathrm{M}_{\mathrm{w}}$ barley $\beta$-glucan was associated with higher levels of the phylum Bacteroidetes while Firmicutes levels were reduced (89). These alterations were accompanied by reductions in CVD risk factors including BMI, blood pressure and circulating triacylglycerol (TAG) over the 35day study period and the authors identified specific microbial taxa whose abundance correlated with markers of disease risk (including total cholesterol and LDL-C) (89). Another study used fluorescence in situ hybridization with probes specific for selected bacterial genera and showed that consumption of an oatbased granola breakfast cereal was associated with a cholesterollowering effect concomitant with elevated Bifidobacterium and Lactobacillus species. As these species are associated with BSH activity and as members of these species have been previously used as probiotics which can lower serum cholesterol levels, the authors suggested that the lowering of serum cholesterol in this study may be linked to alterations to bile acid metabolism and that further studies are warranted. No significant changes were seen in particular species of Bacteroides, Atopobium, or Clostridium targeted in this study (19).

Overall, intervention studies utilizing sources of $\beta$-glucan suggest that consumption can promote alterations to the gut microbiota with some studies suggesting a potentially beneficial (prebiotic) effect (19).

\section{Mechanisms by Which Oat $\beta$-Glucan may Influence Host Cholesterol Metabolism Through Alterations in BSH Activity of the Microbiome}

Evidence from in vitro fecal fermentation studies and rodent and human intervention studies suggest that oat $\beta$-glucan consumption increases levels of bacteria in the gut with known $\mathrm{BSH}$ activity (reviewed above).

A variety of studies have demonstrated an elevation of Bifidobacterium, Bacteroides, and Lactobacillus species in the gut following oat $\beta$-glucan consumption. These bacterial genera are known to predominately contain BSH-positive species (90). There is therefore good evidence for an effect of oat $\beta$-glucan on the host microbiota with a predicted influence upon those species that are $\mathrm{BSH}$ positive. This would suggest that consumption of oat $\beta$-glucan has the capacity to alter host bile acid profiles. However, further work is necessary to determine if oat $\beta$-glucan can effectively modulate host bile acid profiles in humans as predicted by these microbiota analyses.

There is good evidence that BSH-active probiotic interventions can reduce serum LDL-C providing a direct link between elevated $\mathrm{BSH}$ activity and regulation of host cholesterol [reviewed in Jones et al. (24) and below]. Whilst the evidence for a cholesterol-lowering activity of BSH is strong the precise mechanisms remain elusive and most likely reflect an alteration in both the physico-chemical properties of bile acids and the molecular signaling potential of the bile acid pool for FXR.

Bacterial BSH activity is known to alter the host bile acid signature through deconjugation of conjugated bile acids. Unconjugated bile acids have reduced micellular activity and therefore are less effective mediators of cholesterol absorption in the host relative to conjugated bile acids (24).

In support of this, administration of a strongly $\mathrm{BSH}$ positive probiotic L. reuteri NCIMB 30242 strain to humans lowered serum LDL-C and lowered absolute plasma concentrations of plant sterols (surrogate markers of cholesterol) suggesting decreased inward transport of cholesterol in the gut (23). Therefore, elevated bacterial BSH activity is likely to directly reduce cholesterol uptake from the lumen and this may provide a general mechanism by which BSH regulates systemic cholesterol in the host (24). Unconjugated bile acids are also more likely to be eliminated in the feces thereby driving a requirement for de novo bile acid synthesis and an associated reduction of systemic 
cholesterol (68). Indeed, Joyce et al. (25) showed that expression of highly active L. salivarius BSH could significantly reduce LDL cholesterol, total cholesterol and also serum triglycerides in mice. In humans BSH-active L. acidophilus administered over 6 weeks could reduce plasma levels of both total cholesterol and LDLcholesterol (91). BSH active L. reuteri NCIMB 30242 significantly reduced LDL-C, total cholesterol in a human randomized controlled study with elevated free bile acid levels detected in circulation $(22,23)$.

The reduced reabsorption of bile acids also reduces their potential to interact with FXR and may lead to a reduction in stimulation of FXR. However, unconjugated bile acids also can act as potent ligands for the FXR and are also the substrates for further bacterial conversions of bile acids to secondary bile acids which are also potent FXR agonists. Therefore, another possible hypothesis is that FXR is activated in the gut by $\mathrm{BSH}$ activity leading to increased FXR signaling in the gut and expression of the hormone FGF19 by enterocytes leading to a reduction in hepatic bile acid synthesis. More research is necessary to understand the chemical and physiological parameters which dictate whether FXR is stimulated through local bacterial BSH activity. In the absence of such research we herein consider the evidence for two potential mechanisms by which elevated $\mathrm{BSH}$ activity may impact host systemic cholesterol levels. In hypothesis 1 FXR is not activated and de novo bile acid synthesis is increased. In hypothesis 2 FXR is activated and FGF19 is elevated resulting in a reduction in bile acid synthesis and an increase in other mechanisms by which cholesterol levels are potentially modulated in the host. Given a number of recent studies which show a decrease in FXR activation in the gut following administration of $\mathrm{BSH}$-active probiotics we favor hypothesis 1 as most likely to represent a scenario in which BSH activity is increased in the gut microbiota following dietary interventions (as is potentially the case for $\beta$-glucan consumption).

\section{Hypothesis 1: Elevated Bacterial BSH Activity Can Reduce Engagement of FXR in the Intestine, Increase Bile Acid Excretion and Increase de novo Synthesis of Bile Acids in the Liver (Figure 1)}

Conjugated bile acids are actively reabsorbed via specific transport systems into enterocytes in the ileum whereas unconjugated bile acids are not subject to this specific reuptake system and are passively absorbed at a lower rate (92). BSH activity decreases the levels of conjugated bile acids which can be actively transported and recent in vivo evidence suggests that the resulting deconjugated bile acids are less efficiently reabsorbed into enterocytes (93). Unconjugated bile acids then enter the colon where conversions to secondary bile acids can take place (94) or are excreted in feces. As the FXR is an intracellular nuclear receptor lower levels of cellular adsorption of bile acids will lead to a lowering of FXR activation in the terminal ileum.

In support of this hypothesis it has been shown that monocolonization of germ-free rats with BSH-active bacterial species significantly promotes fecal excretion of bile acids (95). More recently, oral inoculation of rodent models with $\mathrm{BSH}-$ producing probiotic bacteria was shown to reduce intestinal FXR activation relative to controls in tandem with an alteration of local bile acid profiles. Inoculation of mice with a highly BSHactive polybiotic mixture of organisms (VSL\#3) significantly reduced FGF15 (a marker of FXR activation) and increased expression of hepatic Cyp7a1 and Cyp8b1 and increased bile acid synthesis (93) (see Figure 1). In a separate study oral administration of L. plantarum CCFM8661 to mice induced similar effects; inhibition of the FXR-FGF axis, elevated Cyp7a1 expression and elevated bile acid synthesis (96). In another study in mice administered a high fat diet oral inoculation with $\mathrm{BSH}$ active $L b$. rhamnosus LGG reduced serum cholesterol in concert with a downregulation in FXR transcription in the liver and increased expression of hepatic Cyp7a1 (but not Cyp8b1) (97). An earlier study also linked the cholesterol-lowering effect of a $L b$. plantarum probiotic strain to an increase in expression of $C y p 7 a 1$ in mice, indicative of downregulation of FXR-mediated feedback (98). Furthermore, a BSH-active probiotic $L b$. reuteri NCIMB 30242 has been shown to reduce serum LDL-C in humans with a concomitant increase in total bile acid levels (99). As bile acids are synthesized from cholesterol, increased de novo synthesis of bile acids contributes to cholesterol catabolism in the host leading to a lowering of systemic cholesterol levels (68).

Another nuclear receptor, LXR, is indirectly repressed by the FXR. Therefore, another consequence of reduced FXR signaling is an elevation of LXR activity. This stimulation of LXR leads to an increase in expression of the cholesterol efflux system ABCG5/8 in enterocytes (100) and increased excretion of cholesterol $(54,101)$. A recent study demonstrated that the BSH-active probiotic strain Lactobacillus plantarum LRCC 5273 reduces serum cholesterol in mice along with an increase in expression of $C y p 7 A 1$, an increase in both hepatic and gut LXR activity and elevated expression of gastrointestinal ABCG5/8 allied with a decrease in expression of the gene encoding NPC1L1 (a cholesterol uptake system) (102). The authors propose a model in which elevated BSH activity promotes TICE mediated through LXR activation which involves elevated excretion of cholesterol from the system and reduced cellular uptake (102). In support of this another study in mice demonstrated that an increase in $\mathrm{BSH}$ activity in the lumen can increase transcription of $A b c g 5 / 8$ concomitant with a reduction in serum cholesterol (25).

Whilst bile acid synthesis is controlled by the gastrointestinalhepatic FXR-FGF axis another mechanism of feedback inhibition is mediated directly via circulating bile acids. Bile acids entering the enterohepatic circulation have the potential to directly influence FXR signaling in the liver, a process which influences de novo bile acid synthesis and cholesterol metabolism (103). A consequence of the elevated excretion of bile acids in feces as outlined above may be reduced re-circulation of bile acids and downregulation of liver FXR activity (24). Downregulation of FXR leads to reduction in SHP and consequently elevated activity of LXR (24). Indeed the recent study cited above suggests that elevated BSH activity in the gut results in elevated LXR expression in the liver in mice (102). The consequences of reduced hepatic FXR signaling include increased expression of Cyp7A1 and therefore increased de novo bile acid synthesis. In addition, LXR activation leads to the expression of hepatic ABCG5/8 that promotes cholesterol excretion into bile (104) and 


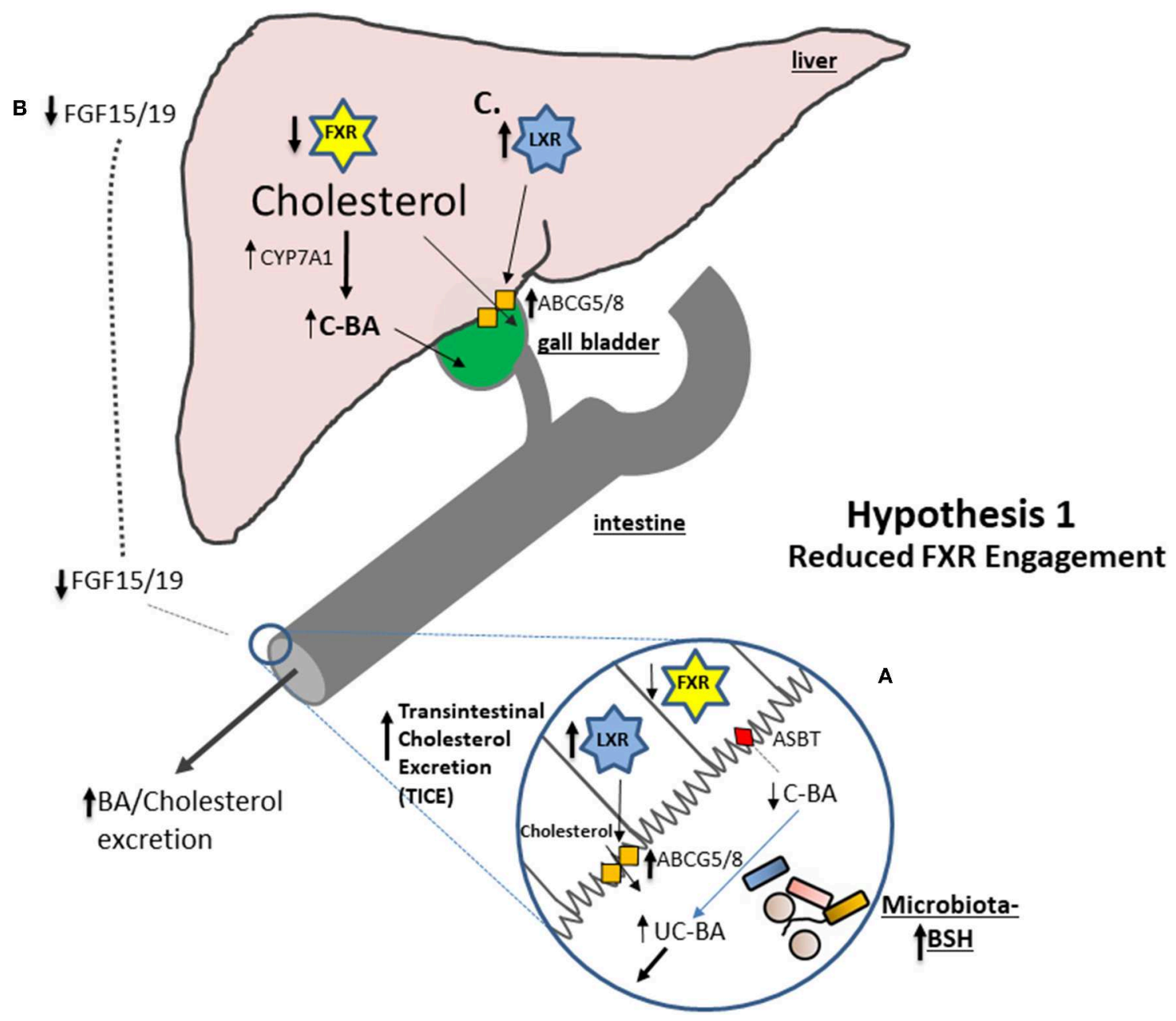

FIGURE 1 | A number of studies suggest that an increase in microbial BSH activity results in a reduction in stimulation of intestinal FXR. (A) Conjugated bile acids (C-BA) are rapidly absorbed in the terminal ileum but BSH activity reduces the amounts of C-BA locally leading to decreased entry of bile acids (BA) into the cell and reduced engagement of Farnesoid X receptor (FXR). Reduced FXR potentiates the capacity for LXR to become activated and studies show that liver orphan receptor (LXR) activation stimulates the Transintestinal Cholesterol Excretion (TICE) pathway in the gut leading to net cholesterol excretion. (B) Reduced engagement of FXR in the ileum reduces fibroblast growth factor 15 (in mice) or 19 (in humans) (FGF15/19) preventing feedback inhibition of Cyp7A1 and increasing de novo synthesis of bile acids from cholesterol thereby reducing systemic cholesterol levels. (C) Increased excretion of bile acids reduces hepatic signaling to FXR which results in increased potential for activation of LXR and elevated expression of $A b c g 5 / 8$ allowing for excretion of cholesterol into the bile.

plays a significant role in the regulation of systemic cholesterol levels (105).

\section{Hypothesis 2: Gastrointestinal FXR Is Activated Through Increased Generation of Unconjugated Bile Acids by Microbial BSH Activity, FGF19 Is Elevated Leading to Downregulation of Hepatic Bile Acid Synthesis and Upregulation of RCT and TICE (Figure 2)}

Whilst both conjugated and unconjugated bile acids can activate the FXR, unconjugated bile acids generated through elevated bacterial BSH activity have a greater ability to enter target cells without a specific transport mechanism (106). There is evidence that FXR is activated via $\mathrm{BSH}$ activity in the gut. One study indicates that administration of a $\mathrm{BSH}$-active probiotic, Lb. reuteri NCIMB 30242 to humans lowers LDL-C with levels of FGF19 trending toward an increase (though the increase was not statistically significant). Furthermore, somewhat counterintuitively, there was evidence for an increase in bile acid synthesis in subjects receiving the probiotic so it is difficult to determine whether the FXR-FGF axis was indeed engaged in this study (99). This is in contrast to numerous studies in animals indicating the opposite effect (see mechanism 1). Therefore, further human intervention studies are needed to determine whether FXR may be stimulated by microbial $\mathrm{BSH}$ activity in humans. Other studies demonstrate that a reduction in BSH activity through administration of antibiotics (107) or the antioxidant Tempol (108) decreases gut bacterial BSH activity leading to a reduction in gastrointestinal FXR signaling in mice. The corollary of these findings would suggest that a physiological 


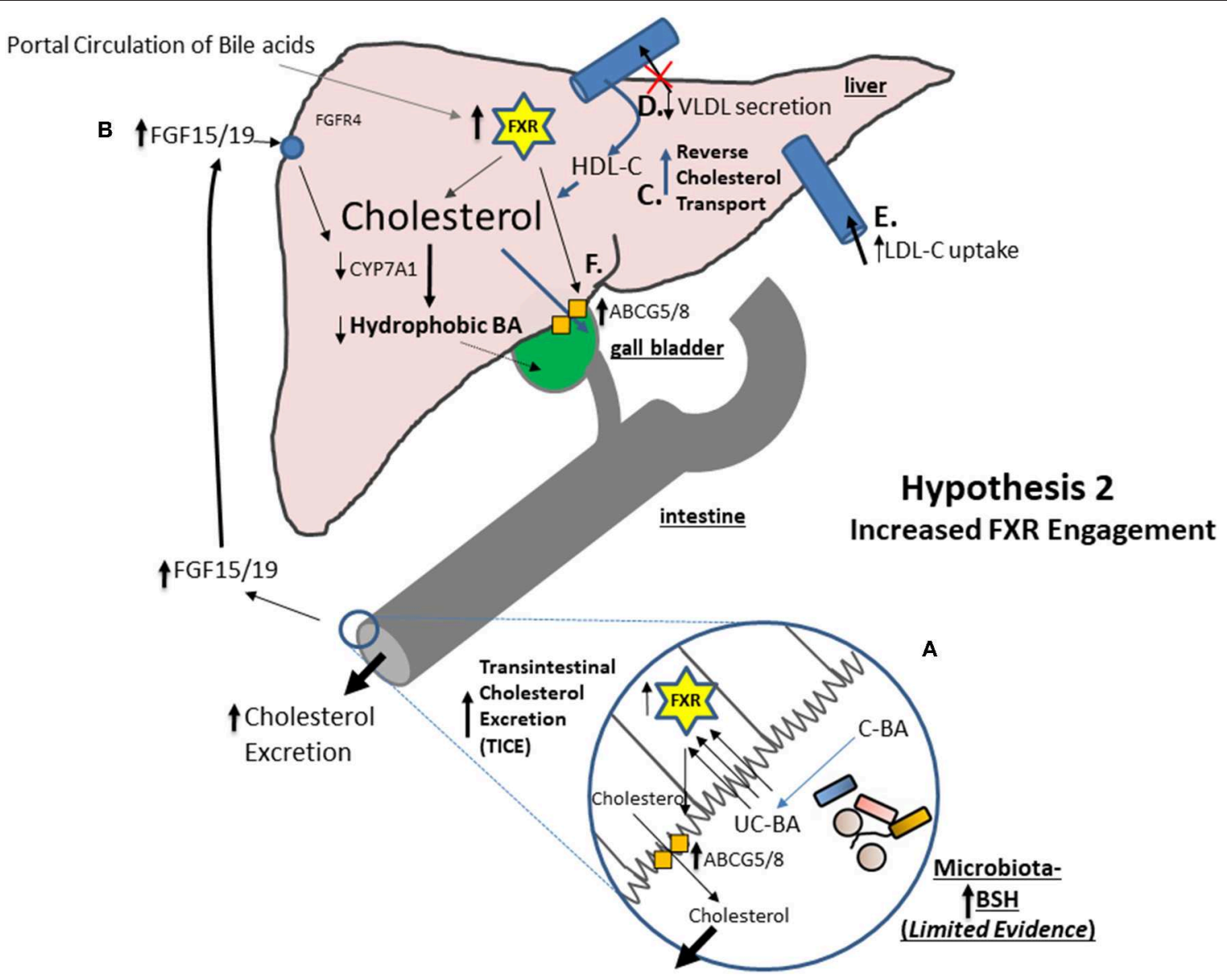

FIGURE 2 | Under specific circumstances which remain unclear the Farnesoid X receptor (FXR) may be stimulated in the gastrointestinal tract. There is some evidence from a single human probiotic study that FXR may be stimulated through BSH activity but further studies are warranted. (A) In a model where gastrointestinal FXR is stimulated unconjugated bile acids (UC-BA) may access the FXR through non-specific passage through cell membranes. (B) There is good evidence that intestinal FXR activation promotes the Transintestinal Cholesterol Excretion (TICE) system for the net efflux of cholesterol into the feces. FXR activation leads to elevated intestinal production of FGF15/19 which feeds back to inhibit bile acid synthesis. Via a process that involves FXR this results in a net reduction in hydrophobic BA species but a relative increase in hydrophilic BA species which are released into the small intestine. As hydrophilic BAs poorly associate with cholesterol this may reduce cellular uptake of cholesterol in the gut. (C) There is also good evidence that elevated hepatic FXR activation increases systemic reverse cholesterol transport (RCT) for the mobilization of cholesterol from macrophages (as HDL-C) to the liver for excretion. (D) There is evidence to suggest that engagement of the FXR reduces the secretion of VLDL into the circulation thereby reducing the systemic circulation of this atherogenic molecule. (E) There is also evidence to suggest that engagement of the FXR increases the uptake of LDL into the liver from the circulation thereby reducing the systemic circulation of this atherogenic molecule. (F) Finally, there is evidence to suggest that FXR activation increases hepatic ABCG5/8 with potential to promote biliary secretion of cholesterol.

role of microbial $\mathrm{BSH}$ is to enhance FXR signaling in the gut $(106,108)$. However, the effects of Tempol or antibiotics upon the microbiota are so profound in these experiments, that it is difficult to equate these results to those expected following consumption of oat $\beta$-glucan where subtle increases in $\mathrm{BSH}$ activity akin to probiotic treatments, are expected.

There is significant evidence to support a role for FXR signaling in cholesterol homeostasis. However, most of this evidence has been generated through the use of potent FXRagonists or through experiments using knock-out mice. There is relatively little evidence directly linking these effects to microbiota changes. Oral delivery of FXR agonists has been shown to decrease systemic LDL-C or non-HDL-C $(68,69)$ and to decrease atherosclerotic plaque formation in mouse models of atherosclerosis $(66,68,69)$. Furthermore, mice deleted in FXR display hypercholesterolemia $(23,50,109)$. The mechanisms by which the FXR regulates systemic cholesterol metabolism are thought to include regulation of cellular LDL-C uptake, reduction in plasma VLDL, modulation of plasma HDL-C levels, regulation of reverse cholesterol transport (RCT) and possible regulation of trans-intestinal cholesterol excretion (TICE) [reviewed in $\mathrm{Li}$ and Chiang (27)]. Studies in animal models suggest that FXR agonists can lower plasma VLDL levels $(110,111)$. Recent studies demonstrate that FXR agonists reduce hepatic secretion of VLDL by suppressing expression of PLA2G12B, a protein involved in assembly and secretion of potentially atherogenic VLDL (111). In addition, FXR knockout mice demonstrate reduced clearance of plasma HDL-C and further studies suggest that hepatic FXR 
activation increases RCT from macrophages and fecal excretion of cholesterol $(69,100)$.

The cholesterol transport system ABCG5/8 is positively regulated by FXR (in addition to regulation via LXR) and there is evidence to suggest that FXR activation increases hepatic ABCG5/8 with potential to promote biliary secretion of cholesterol [reviewed in Li and Chiang (27)]. ABCG5/8 is also expressed in enterocytes where it plays a significant role in the elimination of cholesterol into the gut lumen through TICE [reviewed in de Boer et al. (54)]. In mice engagement of hepatic FXR using an agonist significantly reduced serum cholesterol, increased RCT and increased the hydrophilic bile acid pool. As hydrophilic bile acids less efficiently associate with cholesterol this was thought to be a factor which reduced intestinal absorption of cholesterol thereby lowering systemic cholesterol levels (112). Other studies have indicated that FXR agonists stimulate TICE to significantly increase cholesterol excretion. TICE was not evident in knock-out mice lacking intestinal FXR indicating that this pathway is highly dependent upon FXR activation in the gut (101). However it should be appreciated that activation of LXR in the gut (allied to downregulation of FXR) can also induce the TICE system (see mechanism 1) (101).

\section{Propionate and Other Short-Chain Fatty Acids (SCFA)}

SCFAs are microbial metabolites that are particularly associated with fermentation of dietary fibers. Exposure of fecal bacteria to oat bran fractions using in vitro model systems has demonstrated an ability of oat $\beta$-glucan to stimulate SCFA production by the gut microbiota $(81,113-115)$. In many of the studies propionate predominated amongst the SCFAs stimulated by oat bran fermentation $(81,113,114)$. Animal studies support the finding that oat fermentation alters the microbiota and elevates SCFA production in the colon. In mice, oat-derived $\beta$-glucan consumption led to an alteration to the fecal microbiota and an elevated level of propionate in the colon (84) whilst in another recent study in $\mathrm{ApoE}^{-}$mice feeding of oat $\beta$-glucan led to elevated n-butyrate levels (32). In rats, oat $\beta$-glucan feeding also increased overall SCFA levels $(87,116,117)$. Similarly porcine feeding studies indicate an increase in overall SCFA levels following consumption of oat $\beta$-glucans or similar feed additives $(118,119)$ with elevated butyrate in particular being evident in some studies $(120,121)$. In one study SCFAs were lower in pigs fed oat products relative to the control (122). However, overall the animal feeding studies suggest an influence of oat $\beta$-glucan on the gut microbiota which results in an elevated production of SCFAs.

Whilst studies have examined the effects of oats on humanderived microbial populations in ex vivo models, relatively few studies have examined the effects of oat consumption on SCFA production in human intervention studies. In a randomized clinical trial oat $\beta$-glucan resulted in reduced cholesterol concomitant with an increase in total SCFA and in particular butyrate (123). A similar study determined that total SCFAs were elevated in subjects fed a $\beta$-glucan rich oat bran for 8 weeks (124). Another randomized clinical trial demonstrated the efficacy of bran $\beta$-glucans in lowering cholesterol with effects linked to an increase in SCFAs (in particular propionate) concomitant with changes to the microbiota (125). Another study demonstrated an increase in fecal SCFAs in subjects consuming a high $M_{W}$ barley $\beta$-glucan in concert with an increase in fecal bile acid excretion (126). The same effects were not seen in subjects consuming a low $\mathrm{M}_{\mathrm{w}}$ barley $\beta$-glucan (126). In contrast, a recent study which investigated the effects of a whole grain oat granola upon microbiota markers failed to show an influence upon fecal SCFA levels despite a significant lowering of TC and LDL cholesterol levels (19). The authors suggested that in future studies measurement of circulating SCFAs would be more informative in order to determine physiologically relevant systemic effects.

Indeed, as SCFAs are rapidly absorbed by enterocytes in the gut their presence may be a rather transient marker of gut microbial activity. In this respect fecal fermentation studies with controlled human microbiota samples may represent an accurate measure of the influence of biotic factors on SCFA production in the gut (as the SCFA will not be absorbed in this model). A study by Carlson et al. recently demonstrated that a commercially available source of oat $\beta$-glucan significantly increased propionate production by the microbiota in a human fecal fermentation system (127). The work confirms other earlier studies which demonstrated that addition of sources of oat $\beta$ glucan to in vitro microbial fermentation systems can increase SCFA (in particular propionate) production $(81,114,128)$.

The signaling and health-promoting effects of SCFAs are relatively well-established (129). Luminal propionate engages specific receptors (GPR41 and GPR43) to influence local production of hormones, and regulates satiety and intestinal transit times (129). Propionate and butyrate also mediate antiinflammatory effects in the host through interaction with GPR43 expressed in Treg cells (in the case of propionate) or interaction with GPR109A on dendritic cells (in the case of butyrate) (129, 130). Of the SCFAs, propionate in particular plays a significant role in modulation of cellular lipid metabolism, resulting in effects that may be linked to the proposed cholesterol-lowering effect of propionate (30). However more studies are required to definitively prove these links and address mechanisms (30). Exposure of rat hepatocytes to propionate in culture resulted in a reduction in cellular cholesterol synthesis (131) an effect that was potentially linked to reductions in acetyl-CoA synthase activity or acetate uptake, both of which are features of cholesterol metabolism [reviewed in Hosseini et al. (30)].

A number of studies have proposed an effect of SCFAs (including propionate) in the lowering of cholesterol markers in animal or human systems. Positive correlations between the cholesterol-lowering properties of probiotics and elevated SCFAs (notably propionate and butyrate) have been made in murine and rat intervention studies $(132,133)$. Positive correlations have also been made between the cholesterol-lowering properties of fibers other than $\beta$-glucan and elevated levels of SCFAs $(134,135)$.

More direct causal effects can be seen when subjects either consume dietary SCFAs or they are directly infused. In rats dietary supplementation with propionate led to a significant decrease in plasma TC levels (136). A more recent study demonstrated that dietary feeding of individual SCFAs 
(propionate, acetate or butyrate) was sufficient to lower TC and non-HDL cholesterol in hypercholesterolaemic hamsters (137). The effects were correlated with increased bile acid excretion in the feces and elevated expression of enzymes involved in bile acid synthesis (137). A recent study demonstrated that oral infusion of a mixture of acetate, butyrate and propionate can reduce serum cholesterol levels in pigs (138). In contrast a previous study in which pigs were infused with propionate directly into the caecum failed to show a cholesterol-lowering effect (139). To our knowledge studies investigating the effects of dietary supplementation with SCFAs on cholesterol levels in humans are relatively limited. In two separate studies consumption or infusion of additional dietary propionate did not alter markers of lipid metabolism (140) or cholesterol (141) in healthy volunteers.

\section{Microbial Exopolysaccharide (EPS) in Cholesterol Homeostasis}

In addition to modulation of bile acid profiles and production of SCFAs, gut microorganisms can influence the host through toll-like receptor agonists and other microbial components (including EPS). EPS is composed of repeating carbohydrate moieties, either strongly or loosely associated with the peptidoglycan layer of many lactic acid bacteria (including Lactobacillus and Bifidobacterium species) (142,143). Given that these bacterial populations may be altered by consumption of oat $\beta$-glucans (19) we predict that EPS is likely to play a role as an effector of microbe-host crosstalk influenced by potential prebiotic effects of $\beta$-glucans. EPS is thought to protect the bacterial cell from environmental stressors and to improve survival in the GI tract but also plays a role in microbe-host interactions [reviewed in Ryan et al. (143)]. Production of EPS has been associated with the immunoregulatory properties of specific strains used as probiotics (144) and also plays a role in lowering of cholesterol. The Pediococcus parvulus strain 2.6 produces an EPS that resembles the structure of oat $\beta$ glucan (143) and the strain has been shown to regulate serum cholesterol in hypercholesterolaemic volunteers consuming a fermented beverage made with $P$. parvulus 2.6 (145). London et al. showed that a Lactobacillus strain engineered to produce EPS demonstrated a greater cholesterol-lowering effect in a mouse model of atherosclerosis than an isogenic non-producer (146). Furthermore a Lb. mucosae DPC6426 strain which naturally produces high levels of EPS was capable of reducing lipid markers (TC and serum triglyceride) in the same model system (146). EPS extracted from Lactobacillus strains caused a reduction in triacylglycerol lipid accumulation in an in vitro adipocyte model and a reduction in levels of triacylglycerol and cholesterol in murine fat tissue when mice were injected with EPS. The work demonstrated a role for TLR2 in the cholesterol and lipid-lowering effects of EPS (147). Overall the data suggest that alteration to the relative levels and chemical isotypes of EPS in the GI tract through alterations to the microbiota may have the potential to modulate host cholesterol metabolism, potentially through a TLR2-mediated mechanism. However, further mechanistic studies are required.

\section{Microbial Cholesterol Assimilation and Metabolism}

Numerous bacterial genera found throughout the biosphere have the capacity to metabolize cholesterol. Genomic approaches have identified likely mechanisms by which some species can degrade cholesterol but others remain uncharacterized [reviewed in Garcia et al. (148) and Bergstrand et al. (149)]. A number of gut-dwelling bacterial species have the capacity to transport and/or metabolize cholesterol with the potential mechanisms being established in Eubacterium coprostanoligenes (148) an organism that can actively metabolize cholesterol to coprostanol in the GI tract in animal models $(150,151)$. Lactobacillus acidophilus, Lb., casei, and Lb. bulgaricus have been shown to assimilate cholesterol and to reduce cholesterol to coprostanol through the activity of a cholesterol reductase (152). Rationally selected Lactobacillus strains were capable of reducing serum TC and LDL cholesterol in rats fed a lipid-rich diet, a finding that correlated with elevated SCFAs and bile acid excretion in these animals (132). Recent work has identified that Bacteroides spp. isolated from the gut can produce a compound called commendamide which has the capacity to degrade cholesterol and may represent a bacterial adaptation to the gut environment (153). Human intervention studies have indicated an increase in Bacteroidetes in humans following consumption of $\beta$-glucan (89), so there is potential for this to represent a mechanism by which microbiota changes may influence cholesterol metabolism in the host. More work is necessary to establish the cholesterolmetabolizing activities of the gut microbiota in health and disease. However, it is clear that alterations to gut microbial community structure have the potential to alter this important physiological function.

\section{CONCLUSIONS AND FUTURE DIRECTIONS}

The significant clinical evidence for the cholesterol-lowering effects of $\beta$-glucan has led health authorities in the US, Europe and elsewhere to permit health claims attributing a lowering of CVD risk to consumption of specific amounts (generally $3 \mathrm{~g}$ per day) of $\beta$-glucan. The mechanisms by which $\beta$-glucan may lower host cholesterol levels are thought to be linked to an ability to prevent re-circulation or enhance excretion of bile acids, effects that are potentially related to the gel-forming properties of $\beta$ glucan. As bile acids are a major repository of cholesterol in the host this leads to an overall reduction in cholesterol from the system.

However, in recent years our knowledge of both cholesterol metabolism and the physiological role of the gut microbiota has increased significantly. It has become clear that diet (including consumption of $\beta$-glucans) has the potential to significantly alter the composition of the gut microbiota. In turn studies have shown that the composition of the gut microbiota is a major regulator of both cholesterol and bile acid metabolism in the host. Studies in pigs have shown that $\beta$-glucan feeding alters the ability of intestinal cells to reabsorb bile acids and also alters the bile acid profile in the host, suggesting that 
changes in the microbiota are concomitant with the cholesterollowering effect (65). Other studies have confirmed an apparent "prebiotic" effect whereby the microbiota is altered through consumption of oat $\beta$-glucan in a manner that is suggestive of an ability to alter the bile acid metabolizing potential of the gut microbial community (19). In the absence of studies which precisely analyze the effect of $\beta$-glucan consumption on both the microbiota and bile acid profiles we outlined two hypotheses by which cholesterol metabolism may be impacted by gut microbiota-mediated alterations (section Mechanisms by Which Oat $\beta$-Glucan May Influence Host Cholesterol Metabolism Through Alterations in BSH Activity of the Microbiome). We propose a microbe-centered model in which microbial bile acid metabolism results in reduced engagement of the host bile acid receptor FXR, stimulating enhanced de novo bile acid synthesis and enhanced TICE (Figure 1). Furthermore, in this review we outline that other microbe-host interactions may contribute to the cholesterol-lowering effects of $\beta$-glucan though stimulation of SCFA production, cholesterol degradation or via the effects of microbial EPS.

We propose that future studies should utilize a systems biology approach toward understanding the complex interplay between $\beta$-glucan, the microbiota and mechanisms in the

\section{REFERENCES}

1. Tiwari U, Cummins E. Meta-analysis of the effect of beta-glucan intake on blood cholesterol and glucose levels. Nutrition. (2011) 27:1008-16. doi: 10.1016/j.nut.2010.11.006

2. Whitehead A, Beck EJ, Tosh S, Wolever TM. Cholesterol-lowering effects of oat beta-glucan: a meta-analysis of randomized controlled trials. Am J Clin Nutr. (2014) 100:1413-21. doi: 10.3945/ajcn.114.086108

3. Ho HV, Sievenpiper JL, Zurbau A, Blanco Mejia S, Jovanovski E, AuYeung F, et al. The effect of oat beta-glucan on LDL-cholesterol, non-HDLcholesterol and apoB for CVD risk reduction: a systematic review and metaanalysis of randomised-controlled trials. Br J Nutr. (2016) 116:1369-82. doi: 10.1017/S000711451600341X.

4. Wolever TM, Tosh SM, Gibbs AL, Brand-Miller J, Duncan AM, Hart V, et al. Physicochemical properties of oat beta-glucan influence its ability to reduce serum LDL cholesterol in humans: a randomized clinical trial. Am J Clin Nutr. (2010) 92:723-32. doi: 10.3945/ajcn.2010.29174

5. Ellegard L, Andersson H. Oat bran rapidly increases bile acid excretion and bile acid synthesis: an ileostomy study. Eur J Clin Nutr. (2007) 61:938-45. doi: 10.1038/sj.ejcn.1602607.

6. Braaten JT, Wood PJ, Scott FW, Wolynetz MS, Lowe MK, BradleyWhite $\mathrm{P}$, et al. Oat beta-glucan reduces blood cholesterol concentration in hypercholesterolemic subjects. Eur J Clin Nutr. (1994) 48:465-74.

7. European Commission. Commission Regulation (EU) No 1160/2011 of 14 November 2011 on the Authorisation and Refusal of Authorisation of Certain Health Claims Made on Foods and Referring to the Reduction of Disease Risk. (2011). Available online at: http://eur-lex.europa.eu/legal-content/EN/TXT/ PDF/?uri=CELEX:32011R1160andfrom=EN (accessed November 14, 2017).

8. European Commission. Commission Regulation (EU) No 432/2012 of 16 May 2012 Establishing a List of Permitted Health Claims Made on Foods, Other Than Those Referring to the Reduction of Disease Risk and to Children's Development and Health. (2012). Available online at: http:// eur-lex.europa.eu/legal-content/EN/ALL/?uri=CELEX\%3A32012R0432 (accessed November 14, 2017).

9. European Commission. Commission Regulation (EU) No 1048/2012 of 8 November 2012 on the Authorisation of a Health Claim Made on Foods and Referring to the Reduction of Disease Risk. (2012). Available host that regulate serum cholesterol levels. Data which links consumption of $\beta$-glucan to bile acid changes in the host and identifies host metabolic changes (including to levels of FGF19) will be invaluable for enhancing our understanding of the mechanisms by which oat $\beta$-glucan mediates its cholesterollowering effects.

\section{AUTHOR CONTRIBUTIONS}

SJ and CG wrote and edited the manuscript. AK and LF edited, provided critical feedback, and contributed significantly to the writing of the manuscript.

\section{ACKNOWLEDGMENTS}

SJ and CG acknowledge the funding of APC Microbiome Ireland by the Science Foundation of Ireland Centers for Science, Engineering and Technology (CSET) programme (Grant Number SFI/12/RC/2273). SJ is also funded by SFI-EU Cabala 16/ERA-HDHL/3358. SJ and CG received a contribution to research costs for the writing of this article from PepsiCo. The views expressed in this manuscript are those of the authors and do not necessarily reflect the position or policy of PepsiCo Inc. online at: http://eur-lex.europa.eu/legal-content/EN/TXT/?uri=uriserv:OJ. L_.2012.310.01.0038.01.ENG (accessed November 14, 2017).

10. FSANZ (Food Standards Australia New Zealand). Australia New Zealand Food Standards Code. Schedule 4. Nutrition, Health and Related Claims. (2016) (accessed March 1, 2016).

11. Health Canada. Oat Products and Blood Cholesterol Lowering Summary of Assessment of a Health Claim about Oat Products and Blood Cholesterol Lowering. (2010). Available online at: https://www.canada.ca/content/dam/ hc-sc/migration/hc-sc/fn-an/alt_formats/pdf/label-etiquet/claims-reclam/ assess-evalu/oat_avoine-eng.pdf (accessed November 14, 2017).

12. Stringueta PC, dPHd AM, Pereira Brumano L, Santana Pereira M, Oliveira Pinto M. Public health policies and functional property claims for food in Brazil. In: Eissa AA, editors. Structure and Function of Food Engineering. (2012), p. 307-36.

13. Hobbs JMS, Sogah E, Yeung M. Regulating Health Foods: Policy Challenges and Consumer Condundrums. Northampton: Edward Elgar Publishing (2014).

14. Malaysia. Ministry of Health. Guide to Nutrition Labeling and Claims. (2010). Available online at: https:/extranet.who.int/nutrition/gina/sites/default/ files/MYS\%202010\%20Guide\%20to\%20Nutrition\%20Labelling\%20and \%20Claims.pdf (accessed January 3, 2018).

15. Drug and Food Supervisory Agency of the Republic of Indonesia (2011). Regulation of the Head of the Drug and Food Supervisory Agency of the Republic of Indonesia Number HK.03.1.23.11.11.09909 Year 2011 on the Control of Claims in Labeling and Advertising of Processed Food.

16. Ministry of Food and Drug Safety (Korea). Health Functional Food Code. (2010). Available online at: http://www.mfds.go.kr/files/upload/eng/4. Health_Functioanl_Food_Code_(2010.09).pdf (accessed December 4, 2017).

17. Clemens R, van Klinken BJ. The future of oats in the food and health continuum. Br $\quad J \quad$ Nutr. (2014) 112(Suppl 2):S75-9. doi: $10.1017 /$ S0007114514002724

18. Rose DJ. Impact of whole grains on the gut microbiota: the next frontier for oats? Br J Nutr. (2014) 112(Suppl 2):S44-9. doi: 10.1017/S0007114514002244

19. Connolly ML, Tzounis X, Tuohy KM, Lovegrove JA. Hypocholesterolemic and prebiotic effects of a whole-grain oat-based granola breakfast cereal in a cardio-metabolic "At Risk" population. Front Microbiol. (2016) 7:1675. doi: $10.3389 /$ fmicb.2016.01675 
20. Jonsson AL, Backhed F. Role of gut microbiota in atherosclerosis. Nat Rev Cardiol. (2017) 14:79-87. doi: 10.1038/nrcardio.2016.183

21. Begley M, Hill C, Gahan CG. Bile salt hydrolase activity in probiotics. Appl Environ Microbiol. (2006) 72:1729-38. doi: 10.1128/AEM.72.3.1729-1738.2006.

22. Jones ML, Martoni CJ, Parent M, Prakash S. Cholesterol-lowering efficacy of a microencapsulated bile salt hydrolase-active Lactobacillus reuteri NCIMB 30242 yoghurt formulation in hypercholesterolaemic adults. Br J Nutr. (2011) 107:1505-13. doi: 10.1017/s0007114511004703

23. Jones ML, Martoni CJ, Prakash S. Cholesterol lowering and inhibition of sterol absorption by Lactobacillus reuteri NCIMB 30242: a randomized controlled trial. Eur J Clin Nutr. (2012) 66:1234-41. doi: $10.1038 /$ ejcn.2012.126

24. Jones ML, Tomaro-Duchesneau C, Martoni CJ, Prakash S. Cholesterol lowering with bile salt hydrolase-active probiotic bacteria, mechanism of action, clinical evidence, and future direction for heart health applications. Expert Opin Biol Ther. (2013) 13:631-42. doi: $10.1517 / 14712598.2013 .758706$

25. Joyce SA, MacSharry J, Casey PG, Kinsella M, Murphy EF, Shanahan F, et al. Regulation of host weight gain and lipid metabolism by bacterial bile acid modification in the gut. Proc Natl Acad Sci USA. (2014) 111:7421-6. doi: 10.1073/pnas.1323599111

26. Jones ML, Martoni CJ, Ganopolsky JG, Labbe A, Prakash S. The human microbiome and bile acid metabolism: dysbiosis, dysmetabolism, disease and intervention. Expert Opin Biol Ther. (2014) 14:467-82. doi: $10.1517 / 14712598.2014 .880420$

27. Li T, Chiang JY. Bile acid signaling in metabolic disease and drug therapy. Pharmacol Rev. (2014) 66:948-83. doi: 10.1124/pr.113.008201

28. de Boer JF, Schonewille M, Boesjes M, Wolters H, Bloks VW, Bos $\mathrm{T}$, et al. Intestinal farnesoid $\mathrm{X}$ receptor controls transintestinal cholesterol excretion in mice. Gastroenterology. (2017) 152:1126-38.e1126. doi: 10.1053/j.gastro.2016.12.037

29. Ryan PM, Ross RP, Fitzgerald GF, Caplice NM, Stanton C. Functional food addressing heart health: do we have to target the gut microbiota? Curr Opin Clin Nutr Metab Care. (2015) 18:566-71. doi: 10.1097/MCO.0000000000000224

30. Hosseini E, Grootaert C, Verstraete W, Van de Wiele T. Propionate as a health-promoting microbial metabolite in the human gut. Nutr Rev. (2011) 69:245-58. doi: 10.1111/j.1753-4887.2011.00388.x

31. Connolly ML, Lovegrove JA, Tuohy KM. In vitro evaluation of the microbiota modulation abilities of different sized whole oat grain flakes. Anaerobe. (2010) 16:483-8. doi: 10.1016/j.anaerobe.2010.07.001

32. Ryan PM, London LE, Bjorndahl TC, Mandal R, Murphy K, Fitzgerald $\mathrm{GF}$, et al. Microbiome and metabolome modifying effects of several cardiovascular disease interventions in apo-E(-/-) mice. Microbiome. (2017) 5:30. doi: 10.1186/s40168-017-0246-x

33. Tosh SM. Review of human studies investigating the post-prandial bloodglucose lowering ability of oat and barley food products. Eur J Clin Nutr. (2013) 67:310-7. doi: 10.1038/ejcn.2013.25

34. Ripsin CM, Keenan JM, Jacobs DR Jr, Elmer PJ, Welch RR, Van Horn L, et al. Oat products and lipid lowering. A meta-analysis. JAMA. (1992) 267:331725.

35. FDA (Food and Drug Administration). Health Claims: Soluble Fiber From Certain Foods and the Risk of Coronary Heart Disease. (CHD). Code of Federal Regulations Title 2 Section 101.81. 1997 [updated 2014 Sep 1] (2012). Available online at: www.accessdata.fda.gov/scripts/cdrh/cfdocs/ cfcfr/CFRsearch.cfm? fr $=101.81$

36. AbuMweis SS, Jew S, Ames NP. $\beta$-glucan from barley and its lipid-lowering capacity: a meta-analysis of randomized, controlled trials. Eur J Clin Nutr. (2010) 64:1472-80. doi: 10.1038/ejcn.2010.178

37. Theuwissen E, Mensink RP. Water-soluble dietary fibers and cardiovascular disease. Physiol Behav. (2008) 94:285-92. doi: 10.1016/j.physbeh.2008.01.001

38. Russell DW. The enzymes, regulation, and genetics of bile acid synthesis. Ann Rev Biochem. (2003) 72:137-74. doi: 10.1146/annurev.biochem.72.121801.161712

39. Long SL, Gahan CGM, Joyce SA. Interactions between gut bacteria and bile in health and disease. Mol Aspects Med. (2017) 56:54-65. doi: 10.1016/j.mam.2017.06.002
40. Ridlon JM, Kang D-J, Hylemon PB. Isolation and characterization of a bile acid inducible $7 \alpha$-dehydroxylating operon in Clostridium hylemonae TN271. Anaerobe. (2010) 16:137-46. doi: 10.1016/j.anaerobe.2009.05.004

41. Joyce SA, Gahan CG. Bile acid modifications at the microbe-host interface: potential for nutraceutical and pharmaceutical interventions in host health. Annu Rev Food Sci Technol. (2016) 7:313-33. doi: 10.1146/annurev-food-041715-033159

42. Joyce SA, Gahan CG. Disease-associated changes in bile acid profiles and links to altered gut microbiota. Dig Dis. (2017) 35:169-77. doi: 10.1159/000450907

43. Lefebvre P, Cariou B, Lien F, Kuipers F, Staels B. Role of bile acids and bile acid receptors in metabolic regulation. Physiol Rev. (2009) 89:147-91. doi: 10.1152/physrev.00010.2008

44. Chiang JYL. Bile acids: regulation of synthesis. J Lipid Res. (2009) 50:1955-66. doi: 10.1194/jlr.R900010-JLR200

45. Sayin SI, Wahlström A, Felin J, Jäntti S, Marschall H-U, Bamberg K, et al. Gut microbiota regulates bile acid metabolism by reducing the levels of taurobeta-muricholic acid, a naturally occurring FXR antagonist. Cell Metab. (2013) 17:225-35. doi: 10.1016/j.cmet.2013.01.003

46. Song K-H, Li T, Owsley E, Strom S, Chiang JYL. Bile acids activate fibroblast growth factor 19 signaling in human hepatocytes to inhibit cholesterol 7 $\alpha$-hydroxylase gene expression. Hepatology. (2009) 49:297-305. doi: 10.1002/hep.22627

47. Inagaki T, Choi M, Moschetta A, Peng L, Cummins CL, McDonald $\mathrm{JG}$, et al. Fibroblast growth factor 15 functions as an enterohepatic signal to regulate bile acid homeostasis. Cell Metab. (2005) 2:217-25. doi: 10.1016/j.cmet.2005.09.001

48. Lin BC, Wang M, Blackmore C, Desnoyers LR. Liver-specific activities of FGF19 require klotho beta. J Biol Chem. (2007) 282:27277-84. doi: 10.1074/jbc.M704244200

49. Song K-H, Ellis E, Strom S, Chiang, JY. Hepatocyte growth factor signaling pathway inhibits cholesterol $7 \alpha$-hydroxylase and bile acid synthesis in human hepatocytes. Hepatology. (2007) 46:1993-2002. doi: 10.1002/hep. 21878

50. Sinal CJ, Tohkin M, Miyata M, Ward JM, Lambert G, Gonzalez FJ. Targeted disruption of the nuclear receptor FXR/BAR impairs bile acid and lipid homeostasis. Cell. (2000) 102:731-44. doi: 10.1073/S0092-8674(00)00062-3

51. Zhang Y, Lee FY, Barrera G, Lee H, Vales C, Gonzalez FJ, et al. Activation of the nuclear receptor FXR improves hyperglycemia and hyperlipidemia in diabetic mice. Proc Natl Acad Sci USA. (2006) 103:100611. doi: $10.1073 /$ pnas.0506982103

52. Fang S, Suh JM, Reilly SM, Yu E, Osborn O, Lackey D, et al. Intestinal FXR agonism promotes adipose tissue browning and reduces obesity and insulin resistance. Nat Med. (2015) 21:159-65. doi: 10.1038/nm.3760

53. Pathak P, Xie C, Nichols RG, Ferrell JM, Boehme S, Krausz KW, et al. Intestine farnesoid $\mathrm{X}$ receptor agonist and the gut microbiota activate $\mathrm{G}$ protein bile acid receptor-1 signaling to improve metabolism. Hepatology. (2018) 68:1574-88. doi: 10.1002/hep.29857

54. de Boer JF, Kuipers F, Groen AK. Cholesterol transport revisited: a new turbo mechanism to drive cholesterol excretion. Trends Endocrinol Metab. (2018) 29:123-33. doi: 10.1016/j.tem.2017.11.006

55. Temel RE, Brown JM. A new model of reverse cholesterol transport: enTICEing strategies to stimulate intestinal cholesterol excretion. Trends Pharmacol Sci. (2015) 36:440-51. doi: 10.1016/j.tips.2015. 04.002

56. Tall AR, Yvan-Charvet L. Cholesterol, inflammation and innate immunity. Nat Rev Immunol. (2015) 15:104-16. doi: 10.1038/nri3793

57. Wood PJ, Braaten JT, Scott FW, Riedel KD, Wolynetz MS, Collins MW. Effect of dose and modification of viscous properties of oat gum on plasma glucose and insulin following an oral glucose load. Br J Nutr. (1994) 72:731-43.

58. Wood PJ, Beer MU, Butler G. Evaluation of role of concentration and molecular weight of oat beta-glucan in determining effect of viscosity on plasma glucose and insulin following an oral glucose load. Br J Nutr. (2000) 84:19-23. doi: 10.1017/S0007114500001185

59. McRorie JW Jr, McKeown NM. Understanding the physics of functional fibers in the gastrointestinal tract: an evidence-based approach to resolving enduring misconceptions about insoluble and soluble fiber. J Acad Nutr Diet. (2017) 117:251-64. doi: 10.1016/j.jand.2016.09.021 
60. Andersson KE, Svedberg KA, Lindholm MW, Oste R, Hellstrand $\mathrm{P}$. Oats (Avena sativa) reduce atherogenesis in LDL-receptor-deficient mice. Atherosclerosis. (2010) 212:93-9. doi: 10.1016/j.atherosclerosis.2010. 05.001

61. Tong LT, Guo L, Zhou X, Qiu J, Liu L, Zhong K, et al. Effects of dietary oat proteins on cholesterol metabolism of hypercholesterolaemic hamsters. J Sci Food Agric. (2016) 96:1396-401. doi: 10.1002/js fa.7236

62. Marlett JA, Hosig KB, Vollendorf NW, Shinnick FL, Haack VS, Story JA. Mechanism of serum cholesterol reduction by oat bran. Hepatology. (1994) 20:1450-7.

63. Lia A, Hallmans G, Sandberg AS, Sundberg B, Aman P, Andersson H. Oat beta-glucan increases bile acid excretion and a fiber-rich barley fraction increases cholesterol excretion in ileostomy subjects. Am J Clin Nutr. (1995) 62:1245-51. doi: 10.1093/ajcn/62.6.1245

64. Andersson M, Ellegard L, Andersson H. Oat bran stimulates bile acid synthesis within $8 \mathrm{~h}$ as measured by 7alpha-hydroxy-4-cholesten-3-one. Am J Clin Nutr. (2002) 76:1111-6. doi: 10.1093/ajcn/76.5.1111

65. Gunness P, Michiels J, Vanhaecke L, De Smet S, Kravchuk O, Van de Meene A, et al. Reduction in circulating bile acid and restricted diffusion across the intestinal epithelium are associated with a decrease in blood cholesterol in the presence of oat beta-glucan. FASEB J. (2016) 30:4227-38. doi: 10.1096/fj.201600465R

66. Wainfan E, Henkin G, Rice LI, Marx W. Effects of antibacterial drugs on the total cholesterol balance of cholesterol-fed mice. Arch Biochem Biophys. (1952) 38:187-93.

67. Kellogg T, Wostmann B. The response of germfree rats to dietary Cholesterol. Germ-Free Biol Exp Clin Aspects. (1969) 293-295. doi: 10.1007/978-1-4899-6495-3_37

68. Wostmann BS, Wiech NL, Kung E. Catabolism and elimination of cholesterol in germfree rats. J Lipid Res. (1966) 7:77-82.

69. Kellogg TF, Wostmann BS. Fecal neutral steroids and bile acids from germfree rats. J Lipid Res. (1969) 10:495-503.

70. Bartizal KF Jr, Beaver MH, Wostmann BS. Cholesterol metabolism in gnotobiotic gerbils. Lipids. (1982) 17:791-7.

71. Turnbaugh PJ, Ley RE, Mahowald MA, Magrini V, Mardis ER, Gordon JI. An obesity-associated gut microbiome with increased capacity for energy harvest. Nature. (2006) 444:1027-31. doi: 10.1038/nature05414

72. Turnbaugh PJ, Hamady M, Yatsunenko T, Cantarel BL, Duncan A, Ley RE, et al. A core gut microbiome in obese and lean twins. Nature. (2009) 457:480-4. doi: 10.1038/nature07540

73. Ley RE, Turnbaugh PJ, Klein S, Gordon JI. Microbial ecology: human gut microbes associated with obesity. Nature. (2006) 444:1022-3. doi: $10.1038 / 4441022$ a

74. Backhed F, Ding H, Wang T, Hooper LV, Koh GY, Nagy A, et al. The gut microbiota as an environmental factor that regulates fat storage. Proc Natl Acad Sci USA. (2004) 101:15718-23. doi: 10.1073/pnas.0407076101

75. Turnbaugh PJ, Ridaura VK, Faith JJ, Rey FE, Knight R, Gordon JI. The effect of diet on the human gut microbiome: a metagenomic analysis in humanized gnotobiotic mice. Sci Transl Med. (2009) 1:6ra14. doi: $10.1126 /$ scitranslmed.3000322

76. Ridaura VK, Faith JJ, Rey FE, Cheng J, Duncan AE, Kau AL, et al. Gut microbiota from twins discordant for obesity modulate metabolism in mice. Science. (2013) 341:1241214. doi: 10.1126/science.1241214

77. Le Chatelier E, Nielsen T, Qin J, Prifti E, Hildebrand F, Falony G, et al. Richness of human gut microbiome correlates with metabolic markers. Nature. (2013) 500:541-6. doi: 10.1038/nature12506

78. Islam KB, Fukiya S, Hagio M, Fujii N, Ishizuka S, Ooka T, et al. Bile acid is a host factor that regulates the composition of the cecal microbiota in rats. Gastroenterology. (2011) 141:1773-81. doi: 10.1053/j.gastro.2011.07.046

79. Jayachandran M, Chen J, Chung SSM, Xu B. A critical review on the impacts of beta-glucans on gut microbiota and human health. J Nutr Biochem. (2018) 61:101-10. doi: 10.1016/j.jnutbio.2018.06.010

80. Sanders ME, Merenstein DJ, Reid G, Gibson GR, Rastall RA. Probiotics and prebiotics in intestinal health and disease: from biology to the clinic. Nat Rev Gastroenterol Hepatol. (2019) 16:605-16. doi: 10.1038/s41575-019-0173-3

81. Hughes SA, Shewry PR, Gibson GR, McCleary BV, Rastall RA. In vitro fermentation of oat and barley derived beta-glucans by human faecal microbiota. FEMS Microbiol Ecol. (2008) 64:482-93. doi: 10.1111/j.1574-6941.2008.00478.x

82. Kristek A, Wiese M, Heuer P, Kosik O, Schar MY, Soycan G, et al. Oat bran, but not its isolated bioactive beta-glucans or polyphenols, have a bifidogenic effect in an in vitro fermentation model of the gut microbiota. Br J Nutr. (2019) 121:549-59. doi: 10.1017/S0007114518003501

83. Fehlbaum S, Prudence K, Kieboom J, Heerikhuisen M, van den Broek T, Schuren FHJ, et al. In vitro fermentation of selected prebiotics and their effects on the composition and activity of the adult gut microbiota. Int J Mol Sci. (2018) 19:3097. doi: 10.3390/ijms19103097

84. Luo Y, Zhang L, Li H, Smidt H, Wright AG, Zhang K, et al. Different types of dietary fibers trigger specific alterations in composition and predicted functions of colonic bacterial communities in BALB/c mice. Front Microbiol. (2017) 8:966. doi: 10.3389/fmicb.2017.00966

85. Zhou AL, Hergert N, Rompato G, Lefevre $M$. Whole grain oats improve insulin sensitivity and plasma cholesterol profile and modify gut microbiota composition in C57BL/6J mice. J Nutr. (2015) 145:222-30. doi: 10.3945/jn.114.199778

86. Cani PD, de Vos WM. Next-generation beneficial microbes: the case of Akkermansia muciniphila. Front Microbiol. (2017) 8:1765. doi: $10.3389 /$ fmicb. 2017.01765

87. Drzikova B, Dongowski G, Gebhardt E. Dietary fibre-rich oat-based products affect serum lipids, microbiota, formation of short-chain fatty acids and steroids in rats. Br J Nutr. (2005) 94:1012-25. doi: 10.1079/bjn20051577

88. Metzler-Zebeli BU, Hooda S, Pieper R, Zijlstra RT, van Kessel AG, Mosenthin $\mathrm{R}$, et al. Nonstarch polysaccharides modulate bacterial microbiota, pathways for butyrate production, and abundance of pathogenic Escherichia coli in the pig gastrointestinal tract. Appl Environ Microbiol. (2010) 76:3692-701. doi: 10.1128/AEM.00257-10

89. Wang Y, Ames NP, Tun HM, Tosh SM, Jones PJ, Khafipour E. High molecular weight barley $\beta$-glucan alters gut microbiota toward reduced cardiovascular disease risk. Front Microbiol. (2016) 7:129. doi: 10.3389/fmicb.2016.00129.

90. Jones BV, Begley M, Hill C, Gahan CG, Marchesi JR. Functional and comparative metagenomic analysis of bile salt hydrolase activity in the human gut microbiome. Proc Natl Acad Sci USA. (2008) 105:13580-5. doi: 10.1073/pnas.0804437105

91. Ooi L-G, Liong M-T. Cholesterol-lowering effects of probiotics and prebiotics: a review of in vivo and in vitro findings. Int J Mol Sci. (2010) 11:2499-522. doi: 10.3390/ijms11062499

92. Aldini R, Roda A, Lenzi PL, Ussia G, Vaccari MC, Mazzella G, et al. Bile acid active and passive ileal transport in the rabbit: effect of luminal stirring. Eur J Clin Invest. (1992) 22:744-50.

93. Degirolamo C, Rainaldi S, Bovenga F, Murzilli S, Moschetta A. Microbiota modification with probiotics induces hepatic bile acid synthesis via downregulation of the Fxr-Fgf15 axis in mice. Cell Rep. (2014) 7:12-8. doi: 10.1016/j.celrep.2014.02.032

94. Ridlon JM, Kang DJ, Hylemon PB. Bile salt biotransformations by human intestinal bacteria. J Lipid Res. (2006) 47:241-59. doi: 10.1194/jlr.R500013-JLR200

95. Chikai T, Nakao H, Uchida K. Deconjugation of bile acids by human intestinal bacteria implanted in germ-free rats. Lipids. (1987) 22:669-71.

96. Zhai Q, Liu Y, Wang C, Qu D, Zhao J, Zhang H, et al. Lactobacillus plantarum CCFM8661 modulates bile acid enterohepatic circulation and increases lead excretion in mice. Food Funct. (2019) 10:1455-64. doi: 10.1039/c8fo0 $2554 \mathrm{a}$

97. Kim B, Park KY, Ji Y, Park S, Holzapfel W, Hyun CK. Protective effects of Lactobacillus rhamnosus GG against dyslipidemia in high-fat dietinduced obese mice. Biochem Biophys Res Commun. (2016) 473:530-6. doi: 10.1016/j.bbrc.2016.03.107

98. Jeun J, Kim S, Cho SY, Jun HJ, Park HJ, Seo JG, et al. Hypocholesterolemic effects of Lactobacillus plantarum KCTC3928 by increased bile acid excretion in C57BL/6 mice. Nutrition. (2010) 26:321-30. doi: 10.1016/j.nut.2009.04.011

99. Martoni CJ, Labbe A, Ganopolsky JG, Prakash S, Jones ML. Changes in bile acids, FGF-19 and sterol absorption in response to bile salt hydrolase active L. reuteri NCIMB 30242. Gut Microbes. (2015) 6:57-65. doi: 10.1080/19490976.2015.1005474 
100. Repa JJ, Berge KE, Pomajzl C, Richardson JA, Hobbs H, Mangelsdorf DJ. Regulation of ATP-binding cassette sterol transporters ABCG5 and ABCG8 by the liver X receptors alpha and beta. J Biol Chem. (2002) 277:18793-800. doi: 10.1074/jbc.M109927200

101. van der Veen JN, van Dijk TH, Vrins CL, van Meer H, Havinga R, Bijsterveld $\mathrm{K}$, et al. Activation of the liver $\mathrm{X}$ receptor stimulates transintestinal excretion of plasma cholesterol. J Biol Chem. (2009) 284:19211-9. doi: 10.1074/jbc.M109.014860

102. Heo W, Lee ES, Cho HT, Kim JH, Lee JH, Yoon SM, et al. Lactobacillus plantarum LRCC 5273 isolated from Kimchi ameliorates diet-induced hypercholesterolemia in C57BL/6 mice. Biosci Biotechnol Biochem. (2018) 82:1964-72. doi: 10.1080/09168451.2018.1497939

103. Thomas C, Pellicciari R, Pruzanski M, Auwerx J, Schoonjans K. Targeting bile-acid signalling for metabolic diseases. Nat Rev Drug Discov. (2008) 7:678-93. doi: $10.1038 / \mathrm{nrd} 2619$

104. Watanabe M, Houten SM, Wang L, Moschetta A, Mangelsdorf DJ, Heyman RA, et al. Bile acids lower triglyceride levels via a pathway involving FXR, SHP, and SREBP-1c. J Clin Invest. (2004) 113:1408-18. doi: 10.1172/JCI21025

105. Yu L, Li-Hawkins J, Hammer RE, Berge KE, Horton JD, Cohen JC, et al. Overexpression of ABCG5 and ABCG8 promotes biliary cholesterol secretion and reduces fractional absorption of dietary cholesterol. $J$ Clin Invest. (2002) 110:671-80. doi: 10.1172/JCI16001

106. Parks DJ, Blanchard SG, Bledsoe RK, Chandra G, Consler TG, Kliewer SA, et al. Bile acids: natural ligands for an orphan nuclear receptor. Science. (1999) 284:1365-8.

107. Miyata M, Takamatsu Y, Kuribayashi H, Yamazoe Y. Administration of ampicillin elevates hepatic primary bile acid synthesis through suppression of ileal fibroblast growth factor 15 expression. J Pharmacol Exp Ther. (2009) 331:1079-85. doi: 10.1124/jpet.109.160093

108. Li F, Jiang C, Krausz KW, Li Y, Albert I, Hao H, et al. Microbiome remodelling leads to inhibition of intestinal farnesoid $\mathrm{X}$ receptor signalling and decreased obesity. Nat Commun. (2013) 4:2384. doi: $10.1038 /$ ncomms 3384

109. Balkan J, Kanbagli O, Hatipoglu A, Kucuk M, Cevikbas U, Aykac-Toker $\mathrm{G}$, et al. Improving effect of dietary taurine supplementation on the oxidative stress and lipid levels in the plasma, liver and aorta of rabbits fed on a high-cholesterol diet. Biosci Biotechnol Biochem. (2002) 66:1755-8. doi: 10.1271/bbb.66.1755

110. Bilz S, Samuel V, Morino K, Savage D, Choi CS, Shulman GI. Activation of the farnesoid $\mathrm{X}$ receptor improves lipid metabolism in combined hyperlipidemic hamsters. Am J Physiol Endocrinol Metab. (2006) 290:E71622. doi: 10.1152/ajpendo.00355.2005

111. Liu Q, Yang $\mathrm{M}, \mathrm{Fu} \mathrm{X}$, Liu R, Sun $\mathrm{C}$, Pan $\mathrm{H}$, et al. Activation of farnesoid $\mathrm{X}$ receptor promotes triglycerides lowering by suppressing phospholipase A2 G12B expression. Mol Cell Endocrinol. (2016) 436:93-101. doi: 10.1016/j.mce.2016.07.027

112. Xu Y, Li F, Zalzala M, Xu J, Gonzalez FJ, Adorini L, et al. Farnesoid X receptor activation increases reverse cholesterol transport by modulating bile acid composition and cholesterol absorption in mice. Hepatology. (2016) 64:1072-85. doi: 10.1002/hep.28712

113. Hughes SA, Shewry PR, Li L, Gibson GR, Sanz ML, Rastall RA. In vitro fermentation by human fecal microflora of wheat arabinoxylans. J Agric Food Chem. (2007) 55:4589-95. doi: 10.1021/jf070293g

114. Kim HJ, White PJ. In vitro fermentation of oat flours from typical and high beta-glucan oat lines. J Agric Food Chem. (2009) 57:7529-36. doi: $10.1021 /$ jf900788c

115. Nordlund E, Aura AM, Mattila I, Kosso T, Rouau X, Poutanen K. Formation of phenolic microbial metabolites and short-chain fatty acids from rye, wheat, and oat bran and their fractions in the metabolical in vitro colon model. J Agric Food Chem. (2012) 60:8134-45. doi: 10.1021/jf3008037

116. Shen RL, Dang XY, Dong JL, Hu XZ. Effects of oat beta-glucan and barley beta-glucan on fecal characteristics, intestinal microflora, and intestinal bacterial metabolites in rats. J Agric Food Chem. (2012) 60:11301-8. doi: $10.1021 /$ jf $302824 \mathrm{~h}$

117. Adam CL, Williams PA, Dalby MJ, Garden K, Thomson LM, Richardson AJ, et al. Different types of soluble fermentable dietary fibre decrease food intake, body weight gain and adiposity in young adult male rats. Nutr Metab (Lond). (2014) 11:36. doi: 10.1186/1743-7075-11-36
118. Hooda S, Matte JJ, Vasanthan T, Zijlstra RT. Dietary oat beta-glucan reduces peak net glucose flux and insulin production and modulates plasma incretin in portal-vein catheterized grower pigs. J Nutr. (2010) 140:1564-9. doi: $10.3945 /$ jn.110.122721

119. Gorham JB, Kang S, Williams BA, Grant LJ, McSweeney CS, Gidley MJ, et al. Addition of arabinoxylan and mixed linkage glucans in porcine diets affects the large intestinal bacterial populations. Eur J Nutr. (2017) 56:2193-206. doi: 10.1007/s00394-016-1263-4

120. Metzler-Zebeli BU, Zijlstra RT, Mosenthin R, Ganzle MG. Dietary calcium phosphate content and oat beta-glucan influence gastrointestinal microbiota, butyrate-producing bacteria and butyrate fermentation in weaned pigs. FEMS Microbiol Ecol. (2011) 75:402-13. doi: 10.1111/j.1574-6941.2010.01017.x

121. Metzler-Zebeli BU, Ganzle MG, Mosenthin R, Zijlstra RT. Oat betaglucan and dietary calcium and phosphorus differentially modify intestinal expression of proinflammatory cytokines and monocarboxylate transporter 1 and cecal morphology in weaned pigs. $J$ Nutr. (2012) 142:668-74. doi: $10.3945 /$ in.111.153007

122. Jha R, Rossnagel B, Pieper R, Van Kessel A, Leterme P. Barley and oat cultivars with diverse carbohydrate composition alter ileal and total tract nutrient digestibility and fermentation metabolites in weaned piglets. Animal. (2010) 4:724-31. doi: 10.1017/S1751731109991510

123. Queenan KM, Stewart ML, Smith KN, Thomas W, Fulcher RG, Slavin JL. Concentrated oat beta-glucan, a fermentable fiber, lowers serum cholesterol in hypercholesterolemic adults in a randomized controlled trial. Nutr J. (2007) 6:6. doi: 10.1186/1475-2891-6-6.

124. Nilsson U, Johansson M, Nilsson A, Bjorck I, Nyman M. Dietary supplementation with beta-glucan enriched oat bran increases faecal concentration of carboxylic acids in healthy subjects. Eur J Clin Nutr. (2008) 62:978-84. doi: 10.1038/sj.ejcn.1602816

125. Velikonja A, Lipoglavsek L, Zorec M, Orel R, Avgustin G. Alterations in gut microbiota composition and metabolic parameters after dietary intervention with barley beta glucans in patients with high risk for metabolic syndrome development. Anaerobe. (2019) 55:67-77. doi: 10.1016/j.anaerobe.2018.11.002

126. Thandapilly SJ, Ndou SP, Wang Y, Nyachoti CM, Ames NP. Barley betaglucan increases fecal bile acid excretion and short chain fatty acid levels in mildly hypercholesterolemic individuals. Food Funct. (2018) 9:3092-6. doi: $10.1039 / \mathrm{c} 8 \mathrm{fo} 00157 \mathrm{j}$

127. Carlson JL, Erickson JM, Hess JM, Gould TJ, Slavin JL. Prebiotic dietary fiber and gut health: comparing the in vitro fermentations of beta-glucan, inulin and xylooligosaccharide. Nutrients. (2017) 9:1361. doi: 10.3390/nu9121361

128. Sayar S, Jannink JL, White PJ. Digestion residues of typical and high-betaglucan oat flours provide substrates for in vitro fermentation. J Agric Food Chem. (2007) 55:5306-11. doi: 10.1021/jf070240z

129. Koh A, De Vadder F, Kovatcheva-Datchary P, Backhed F. From dietary fiber to host physiology: short-chain fatty acids as key bacterial metabolites. Cell. (2016) 165:1332-45. doi: 10.1016/j.cell.2016.05.041

130. Smith PM, Howitt MR, Panikov N, Michaud M, Gallini CA, Bohlooly YM, et al. The microbial metabolites, short-chain fatty acids, regulate colonic Treg cell homeostasis. Science. (2013) 341:569-73. doi: 10.1126/science.1241165

131. Lin Y, Vonk RJ, Slooff MJ, Kuipers F, Smit MJ. Differences in propionateinduced inhibition of cholesterol and triacylglycerol synthesis between human and rat hepatocytes in primary culture. Br J Nutr. (1995) 74:197-207.

132. Wang J, Zhang H, Chen X, Chen Y, Menghebilige, Bao Q. Selection of potential probiotic lactobacilli for cholesterol-lowering properties and their effect on cholesterol metabolism in rats fed a high-lipid diet. J Dairy Sci. (2012) 95:1645-54. doi: 10.3168/jds.2011-4768

133. Park S, Kang J, Choi S, Park H, Hwang E, Kang Y, et al. Cholesterol-lowering effect of Lactobacillus rhamnosus BFE5264 and its influence on the gut microbiome and propionate level in a murine model. PLoS ONE. (2018) 13:e0203150. doi: 10.1371/journal.pone.0203150

134. Fechner A, Kiehntopf M, Jahreis G. The formation of short-chain fatty acids is positively associated with the blood lipid-lowering effect of lupin kernel fiber in moderately hypercholesterolemic adults. J Nutr. (2014) 144:599-607. doi: $10.3945 /$ jn.113.186858

135. Chen $\mathrm{Y}, \mathrm{Xu} \mathrm{C}$, Huang $\mathrm{R}$, Song J, Li D, Xia M. Butyrate from pectin fermentation inhibits intestinal cholesterol absorption and 
attenuates atherosclerosis in apolipoprotein E-deficient mice. $J$ Nutr Biochem. (2018) 56:175-82. doi: 10.1016/j.jnutbio.2018. 02.011

136. Illman RJ, Topping DL, McIntosh GH, Trimble RP, Storer GB, Taylor MN, et al. Hypocholesterolaemic effects of dietary propionate: studies in whole animals and perfused rat liver. Ann Nutr Metab. (1988) 32:95-107.

137. Zhao Y, Liu J, Hao W, Zhu H, Liang N, He Z, et al. Structure-specific effects of short-chain fatty acids on plasma cholesterol concentration in male syrian hamsters. J Agric Food Chem. (2017) 65:10984-92. doi: 10.1021/acs.jafc.7b04666

138. Jiao AR, Diao H, Yu B, He J, Yu J, Zheng P, et al. Oral administration of short chain fatty acids could attenuate fat deposition of pigs. PLoS ONE. (2018) 13:e0196867. doi: 10.1371/journal.pone.0196867

139. Beaulieu KE, McBurney MI. Changes in pig serum lipids, nutrient digestibility and sterol excretion during cecal infusion of propionate. J Nutr. (1992) 122:241-5. doi: 10.1093/jn/122.2.241

140. Todesco T, Rao AV, Bosello O, Jenkins DJ. Propionate lowers blood glucose and alters lipid metabolism in healthy subjects. Am J Clin Nutr. (1991) 54:860-5. doi: $10.1093 /$ ajcn/54.5.860

141. Wolever TM, Spadafora P, Eshuis H. Interaction between colonic acetate and propionate in humans. Am J Clin Nutr. (1991) 53:681-7. doi: $10.1093 /$ ajcn/53.3.681

142. Kleerebezem M, Hols P, Bernard E, Rolain T, Zhou M, Siezen RJ, et al. The extracellular biology of the lactobacilli. FEMS Microbiol Rev. (2010) 34:199-230. doi: 10.1111/j.1574-6976.2010.00208.x

143. Ryan PM, Ross RP, Fitzgerald GF, Caplice NM, Stanton C. Sugarcoated: exopolysaccharide producing lactic acid bacteria for food and human health applications. Food Funct. (2015) 6:679-93. doi: 10.1039/c4fo $00529 \mathrm{e}$

144. Rodriguez C, Medici M, Rodriguez AV, Mozzi F, Font de Valdez G. Prevention of chronic gastritis by fermented milks made with exopolysaccharide-producing Streptococcus thermophilus strains. J Dairy Sci. (2009) 92:2423-34. doi: 10.3168/jds.2008-1724

145. Mårtensson $\mathrm{O}$, Biörklund $\mathrm{M}$, Lambo $\mathrm{AM}$, Dueñas-Chasco $\mathrm{M}$, Irastorza $\mathrm{A}$, Holst $\mathrm{O}$, et al. Fermented, ropy, oat-based products reduce cholesterol levels and stimulate the bifidobacteria flora in humans. Nutr Res. (2005) 25:429-42. doi: 10.1016/j.nutres.2005.03.004

146. London LE, Kumar AH, Wall R, Casey PG, O'Sullivan O, Shanahan F, et al. Exopolysaccharide-producing probiotic Lactobacilli reduceserum cholesterol and modify enteric microbiota in ApoE-deficient mice. J Nutr. (2014) 144:1956-62. doi: 10.3945/jn.114.191627

147. Zhang Z, Zhou Z, Li Y, Zhou L, Ding Q, Xu L. Isolated exopolysaccharides from Lactobacillus rhamnosus $\mathrm{GG}$ alleviated adipogenesis mediated by TLR2 in mice. Sci Rep. (2016) 6:36083. doi: 10.1038/srep36083

148. Garcia JL, Uhia I, Galan B. Catabolism and biotechnological applications of cholesterol degrading bacteria. Microb Biotechnol. (2012) 5:679-99. doi: 10.1111/j.1751-7915.2012.00331.x

149. Bergstrand LH, Cardenas E, Holert J, Van Hamme JD, Mohn WW. Delineation of steroid-degrading microorganisms through comparative genomic analysis. MBio. (2016) 7:e00166. doi: 10.1128/mBio.00166-16

150. Li L, Baumann CA, Meling DD, Sell JL, Beitz DC. Effect of orally administered Eubacterium coprostanoligenes ATCC 51222 on plasma cholesterol concentration in laying hens. Poult Sci. (1996) 75:743-5. doi: $10.3382 /$ ps. 0750743

151. Li L, Batt SM, Wannemuehler M, Dispirito A, Beitz DC. Effect of feeding of a cholesterol-reducing bacterium, Eubacterium coprostanoligenes, to germfree mice. Lab Anim Sci. (1998) 48:253-5.

152. Lye HS, Rusul G, Liong MT. Removal of cholesterol by lactobacilli via incorporation and conversion to coprostanol. J Dairy Sci. (2010) 93:1383-92. doi: 10.3168/jds.2009-2574

153. Lynch A, Crowley E, Casey E, Cano R, Shanahan R, McGlacken G, et al. The bacteroidales produce an $\mathrm{N}$-acylated derivative of glycine with both cholesterol-solubilising and hemolytic activity. Sci Rep. (2017) 7:13270. doi: 10.1038/s41598-017-13774-6

\section{Conflict of Interest: AK and LF are employed by PepsiCo, Inc.}

The remaining authors declare that the research was conducted in the absence of any commercial or financial relationships that could be construed as a potential conflict of interest.

Copyright $\odot 2019$ Joyce, Kamil, Fleige and Gahan. This is an open-access article distributed under the terms of the Creative Commons Attribution License (CC BY). The use, distribution or reproduction in other forums is permitted, provided the original author(s) and the copyright owner(s) are credited and that the original publication in this journal is cited, in accordance with accepted academic practice. No use, distribution or reproduction is permitted which does not comply with these terms. 